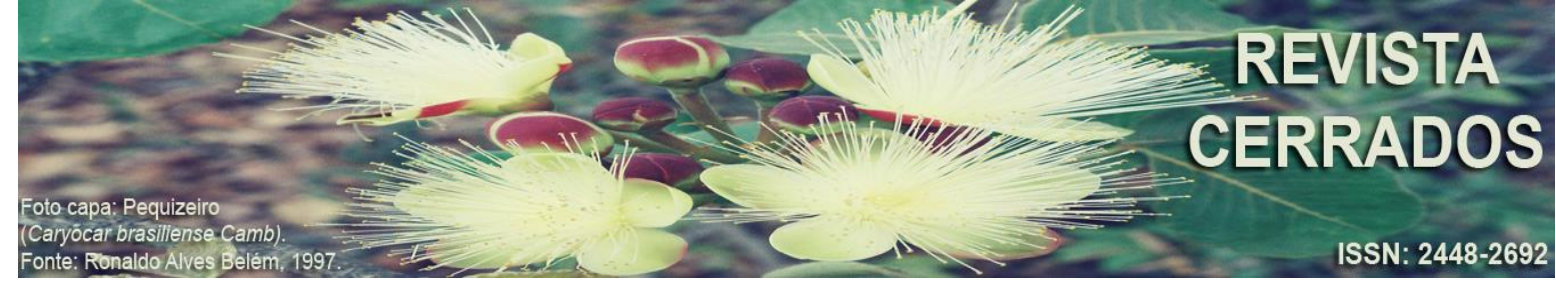

\title{
O USO DE SENSORIAMENTO REMOTO PARA ESTIMAR ÁREA PLANTADA DE CANA-DE-AÇÚCAR EM CAMPOS DOS GOYTACAZES - RJ, BRASIL
}

\section{THE USE OF REMOTE SENSING TO ESTIMATE SUGARCANE PLANTED AREA IN CAMPOS DOS GOYTACAZES - RJ, BRAZIL}

\section{EL USO DE LA DETECCIÓN REMOTA PARA ESTIMAR EL ÁREA PLANTADA DE AZÚCAR EN CAMPOS DOS GOYTACAZES - RJ, BRASIL}

\author{
Antônio Ivo Gomes Barbosa \\ Universidade Federal Fluminense - UFF, Campos dos Goytacazes, \\ Rio de Janeiro, Brasil \\ E-mail: < antonioivo@id.uff.br> \\ Cláudio Henrique Reis \\ Universidade Federal Fluminense - UFF, Campos dos Goytacazes, \\ Rio de Janeiro, Brasil \\ E-mail: < claudioreis@id.uff.br> \\ Universidade Estadual do Norte Fluminense - UENF, Campos dos Goytacazes, \\ Rio de Janeiro, Brasil \\ E-mail: < mendonca@uenf.com> \\ Luca Lämmle \\ Universidade Estadual de Campinas - UNICAMP, Campinas, São Paulo, Brasil \\ E-mail: < lucalammle@ige.unicamp.br>
}

\section{RESUMO}

O Brasil é o maior produtor de cana-de-açúcar, fato que torna importante a realização de minuciosa análise com base na área plantada para que possa ser estimada a produtividade agrícola em questão. Nesse contexto, o presente trabalho teve como objetivo realizar a estimativa da área plantada de cana-de-açúcar no município de Campos dos Goytacazes - RJ ao longo de um ano-safra por meio de Sensoriamento Remoto. A metodologia consistiu no uso das imagens do Satélite LANDSAT-8 referentes ao ano-safra 2017/2018 processadas no 
BARBOSA, A. I. G.; REIS, C. H.; MENDONÇA, J. C.; LÄMMLE, L.

O uso de Sensoriamento Remoto para estimar área plantada de cana-de-açúcar em Campos dos Goytacazes - RJ, Brasil

software livre SPRING versão 5.5.5. As ferramentas que possibilitaram a culminância do resultado final foram: interpretações visuais para delimitação das áreas de plantio e identificação das áreas onde seja permitido efetuar a queima da palha na colheita, utilizando para isto a Linguagem Espacial para Geoprocessamento Algébrico (LEGAL) em consonância com o uso dos modelos digitais de elevação ASTER, SRTM e TOPODATA. Os resultados apontaram uma área plantada de 25.238,34 hectares no referido município, dentre as quais apresentaram declividade superior a 12\% entre 742,14 e 3.159,65 hectares. Os valores totais de área plantada por cana-de-açúcar divergem dos valores calculados pelo IBGE (30.000 ha) e CONAB (19.200 ha) para o referido ano-safra.

Palavras-chave: Geotecnologia. Sistema de Informações Geográficas. Processamento Digital de Imagens. Geografia Física.

\begin{abstract}
Brazil is the largest producer of sugarcane, which is why it is important to conduct a thorough analysis based on the planted area so that the agricultural productivity in question can be estimated. In this context, the present work had as objective to estimate the planted area of sugarcane in the municipality of Campos dos Goytacazes - RJ during a crop year through Remote Sensing. The methodology consisted of the use of landsat- 8 satellite images for the 2017/2018 crop year processed in spring version 5.5.5. The tools that allowed the culmination of the final result were: visual interpretations for delimitation of planting areas and identification of areas where it is allowed to burn straw at harvest, using for this the Spatial Language for Algebraic Geoprocessing (LEGAL) in line with the use of digital lifting models ASTER, SRTM and TOPODATA. The results showed a planted area of 25,238.34 hectares in the municipality, among which they had a slope higher than $12 \%$ between 742.14 and 3,159.65 hectares. The total values of the planted area for sugarcane differ from the values calculated by IBGE $(30,000 \mathrm{ha})$ and CONAB $(19,200 \mathrm{ha})$ for that crop year.
\end{abstract}

Keywords: Geotechnology. Geographic Information System. Digital Image Processing. Physical Geography.

\title{
RESUMEN
}

El Brasil es el mayor productor de caña de azúcar, hecho que hace importante realizar un análisis exhaustivo basado en la superficie plantada para poder estimar la productividad agrícola en cuestión. En este contexto, el presente trabajo tuvo como objetivo estimar el área plantada de caña de azúcar en el municipio de Campos dos Goytacazes - RJ durante una temporada de cultivo a través de Teledetección. La metodología consistió en el uso de imágenes satelitales landsat-8 para la cosecha 2017/2018 procesadas en la versión primaveral 5.5.5. Las herramientas que permitieron la culminación del resultado final fueron: interpretaciones visuales para la delimitación de áreas de plantación e identificación de áreas donde se permite quemar paja en la cosecha, utilizando para ello el Lenguaje Espacial para Geoprocesamiento Algebraico (LEGAL) en línea con el uso de los modelos de elevación digital ASTER, SRTM y TOPODATA. Los resultados mostraron una superficie plantada de 25.238,34 hectáreas en el municipio, entre las que se encuentran una pendiente 
BARBOSA, A. I. G.; REIS, C. H.; MENDONÇA, J. C.; LÄMMLE, L.

O uso de Sensoriamento Remoto para estimar área plantada de cana-de-açúcar em Campos dos Goytacazes - RJ, Brasil

superior al $12 \%$ entre 742,14 y 3.159,65 hectáreas. Los valores totales del área plantada para la caña de azúcar difieren de los valores calculados por IBGE $(30,000$ ha) y CONAB (19,200 ha) para ese año de cultivo.

Palabras-clave: Geotecnología. Sistema de Información Geográfica. Procesamiento de imagen digital. Geografía Física.

\section{INTRODUÇÃO}

Em 1532 os primeiros engenhos foram instalados em território que seria futuramente "brasileiro", mais precisamente em São Vicente (SP) e Olinda (PE), época em que apenas as altas classes sociais eram consumidoras do açúcar oriundo do cultivo da cana (RURAL CENTRO, 2010). O cultivo da cana-de-açúcar foi responsável pela subsistência da economia brasileira devido a constantes avanços tecnológicos observados ao longo de seu desenvolvimento (FURTADO, 1986 apud ARAÚJO e SANTOS, 2013). Sendo assim, a presença da cana de açúcar na economia nacional está diretamente relacionada à construção histórica do Brasil, retratando grandes contribuições na atualidade, com ênfase, principalmente, no contexto agrícola (BISINOTTO, 2018).

Campos dos Goytacazes teve seu primeiro engenho em 1650, sendo que tal fato ocorreu 27 anos antes de sua fundação como Vila de São Salvador (Lamego, 1945) e 112 anos após o início do plantio de cana-de-açúcar na região. A implementação de tal cultura teve a capacidade de alterar a paisagem do norte fluminense deslocando de uma atividade basicamente nômade de criação de gado no século XVI para o sedentarismo do açúcar nas planícies campistas (PARANHOS, 2006).

Com a implementação do Programa Nacional do Álcool (PROÁLCOOL) em 1975, “as usinas foram incentivadas a um desenvolvimento com aumento de sua área cultivada e à instalação, renovação ou ampliação do seu parque industrial" (Smiderles, 2009, p. 48), fato que condicionou em crescente ampliação de usinas até os anos 1980 para a produção de álcool. Desde então, o quantitativo de usinas passou a reduzir-se no município de Campos dos Goytacazes - RJ, e de um total de 11 usinas presentes nos anos 1970, encontramse apenas 3 ativas.

No âmbito da utilização de dados orbitais aplicados à este contexto, existem vários estudos voltados à cana-de-açúcar que utilizaram o Sensoriamento Remoto como 
BARBOSA, A. I. G.; REIS, C. H.; MENDONÇA, J. C.; LÄMMLE, L.

O uso de Sensoriamento Remoto para estimar área plantada de cana-de-açúcar em Campos dos Goytacazes - RJ, Brasil

principal ferramenta de trabalho: Luciano et. al. (2019, p. 223) afirmam, em trabalho que buscou gerar estimativa de produtividade por imagens dos satélites LANDSAT 5, 7 e 8, que "os resultados apontam uma metodologia potencial de estimativa de produtividade da canade-açúcar com imagens de satélite”. De Oliveira et. al. (2019) analisaram a produtividade da água na cultura da cana-de-açúcar em condições de irrigação ou ausência de irrigação a partir de imagens do satélite LANDSAT 8. Outros trabalhos também foram realizados neste sentido (FERNANDES, 2009; AGUIAR et. al, 2009; ALVARES et. al., 2008; BOLES et. al., 2004; ZHANG et. al., 2015; QUARESMA et al., 2018; AYER et al., 2020).

O Brasil tornou-se um importante marco na América Latina no que tange aos estudos a partir de análises com Sensoriamento Remoto graças ao Instituto Nacional de Pesquisas Espaciais (INPE), visto que tal instituição foi decisiva "na consolidação do Sensoriamento Remoto como uma tecnologia de uso em escala nacional, projetando o Brasil como a nação pioneira no hemisfério sul a dominar essa tecnologia." (MENESES e ALMEIDA, 2012, p. 11). O INPE desenvolveu um projeto, já no século XXI, denominado Monitoramento da Cana-de-açúcar via Imagens de Satélite (CANASAT), cujo principal objetivo foi o fornecimento de informações a respeito da distribuição espacial da área cultivada com cana-de-açúcar em regiões específicas do centro-sul brasileiro, por meio de imagens de satélite de Sensoriamento Remoto (INPE, 2019a). Com tal iniciativa, foi possível realizar diversas consultas acerca da localização de canaviais, áreas cultivadas e evolução do cultivo, seja na escala municipal ou estadual, cujas informações podem ser utilizadas pelos setores do agronegócio e meio ambiente, já que ambos estão diretamente ou indiretamente envolvidos com a produção de cana-de-açúcar (MENDONÇA et al., 2011).

A mesorregião Norte-Fluminense do estado do Rio de Janeiro foi abrangida pelo CANASAT nos anos-safra 2010/2011, 2011/2012 e 2012/2013, tornando possível conhecer que a área total cultivada, por exemplo, na safra 2010/2011 foi de 100.105 ha, com destaque para o município de Campos dos Goytacazes, cuja área total cultivada foi descrita como de 63.429 ha (INPE, 2019b). De acordo os dados, o município que mais cresceu no que se refere às áreas de cultivo da cana-de-açúcar foi Cabo Frio, com um saldo positivo de 1.174 ha entre os anos-safra de 2010/2011 e 2012/2013. Em contrapartida, o município que mais regrediu em hectares de áreas de cultivo de cana-de-açúcar foi Campos dos Goytacazes, com um saldo negativo de 2.270 ha entre os mesmos anos-safra citados neste parágrafo. 
O projeto CANASAT deixou de abranger a região norte-fluminense, de modo que a estimativa da área plantada de cana-de-açúcar não mais foi disponibilizada pelo INPE para este recorte regional e que está localizado o município de Campos dos Goytacazes - RJ, atualmente caracterizado por um baixo investimento econômico na produção de cana-deaçúcar sob o foco de impactos limitantes de políticas setoriais e os riscos climáticos que estão envolvidos, tais como a presença de episódios severos de secas ou inundações que prejudicam a qualidade do solo, o que interfere diretamente na produtividade da cultura e da área plantada. Sendo assim, justifica-se a realização deste trabalho pelo fato da não continuidade do projeto mencionado na região e pela importância dessas informações no que se refere ao planejamento ambiental do município, que envolve desde questões hídricas até a própria produtividade da cana-de-açúcar.

Neste sentido, o objetivo do trabalho consiste em estimar a área plantada da canade-açúcar no município de Campos dos Goytacazes por meio de fotointerpretação, Processamento Digital de Imagens (PDI) e produtos que derivam do Sensoriamento Remoto no período que corresponde à safra 2017/2018, além de determinar as áreas com declividade do terreno igual ou superior a $12 \%$ ocupadas pelo plantio da cana-de-açúcar no respectivo ano-safra. Ressalta-se que a Lei Estadual no 5.990 de 20 de junho de 2011 (Rio de Janeiro, 2011) permite a queima da palha da cana-de-açúcar em terrenos com declividade igual ou superior a $12 \%$, por compreender-se que em tais ocasiões o maquinário responsável pela colheita da gramínea não operaria com boa eficiência. Sendo assim, a hipótese é que houve um declínio na produção desde o fim do monitoramento do CANASAT/INPE.

\section{MATERIAIS E MÉTODOS}

A aquisição de dados para atingir o objetivo proposto no presente estudo se deu por meio das seguintes etapas, conforme exibição na Figura 1: 
BARBOSA, A. I. G.; REIS, C. H.; MENDONÇA, J. C.; LÄMMLE, L.

O uso de Sensoriamento Remoto para estimar área plantada de cana-de-açúcar em Campos dos Goytacazes - RJ, Brasil

Figura 1 - Fluxograma das etapas metodológicas apresentadas no presente trabalho

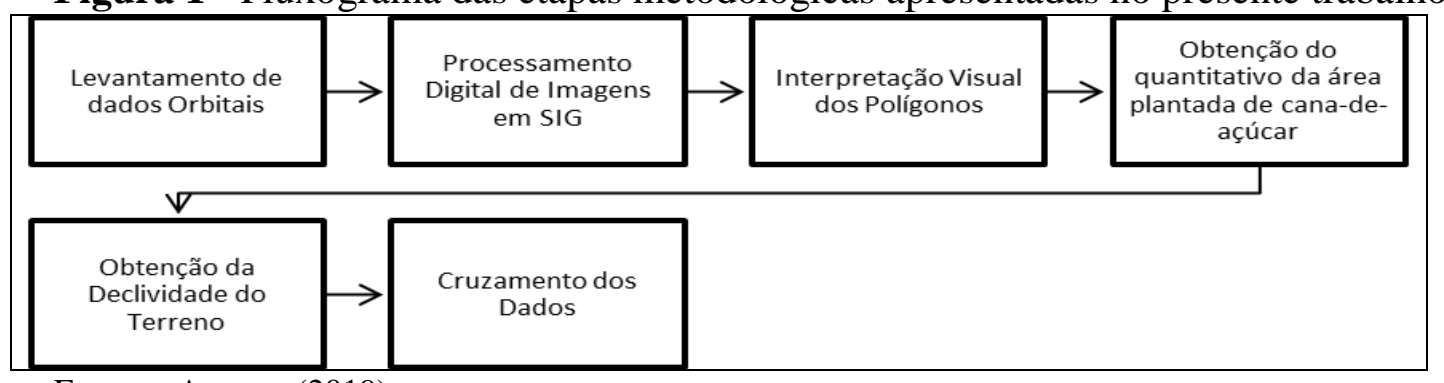

Fonte: Autores (2019).

No Levantamento de Dados Orbitais, foram selecionadas imagens de satélite a serem realizadas os procedimentos metodológicos do presente trabalho. O Processamento Digital de Imagens em SIG se deu a partir do carregamento das imagens selecionadas no software livre SPRING em sua versão 5.5.5, enquanto na Interpretação Visual dos Polígonos (IVP), buscou-se interpretar a área plantada de cana-de-açúcar por meio de chave de interpretação criadas a partir da diferença de cores de reflectância no arranjamento das bandas espectrais do espectro eletromagnético. Na Obtenção do Quantitativo da Área Plantada da Cana-de-Açúcar, foi calculada a área previamente identificada como área plantada no software utilizado. A Obtenção da Declividade do Terreno ocorreu a partir do carregamento de arquivo matricial referente à declividade da área analisada, possibilitando extrair tal informação em seguida. Por fim, o Cruzamento de Dados consistiu em programar o software para que o mesmo retornasse os valores referentes à análise estatística exploratória da área ocupada por cana-de-açúcar, inserida em áreas com declividade maiores ou iguais a $12 \%$.

\section{Área de estudo}

A área de estudo corresponde ao município de Campos dos Goytacazes - RJ, o qual está integrado à Mesorregião Norte Fluminense do estado do Rio de Janeiro, juntamente com os municípios de Carapebus, Cardoso Moreira, Conceição de Macabu, Macaé, Quissamã, São Fidélis, São Francisco de Itabapoana e São João da Barra (IBGE, 1990).

O município em questão apresenta uma área total de 4.032,487 km² $(403.248,7$ ha), sendo um dos maiores do país em extensão territorial, com um contingente populacional estimado de 507.548 habitantes, uma densidade demográfica de 115,16 hab/km² e um PIB per 
BARBOSA, A. I. G.; REIS, C. H.; MENDONÇA, J. C.; LÄMMLE, L.

O uso de Sensoriamento Remoto para estimar área plantada de cana-de-açúcar em Campos dos Goytacazes - RJ, Brasil

capita de 43.013,04 reais (IBGE, 2019). O mapa de localização da área de estudo é apresentado na Figura 2:

Figura 2 - Mapa de localização da área de estudo

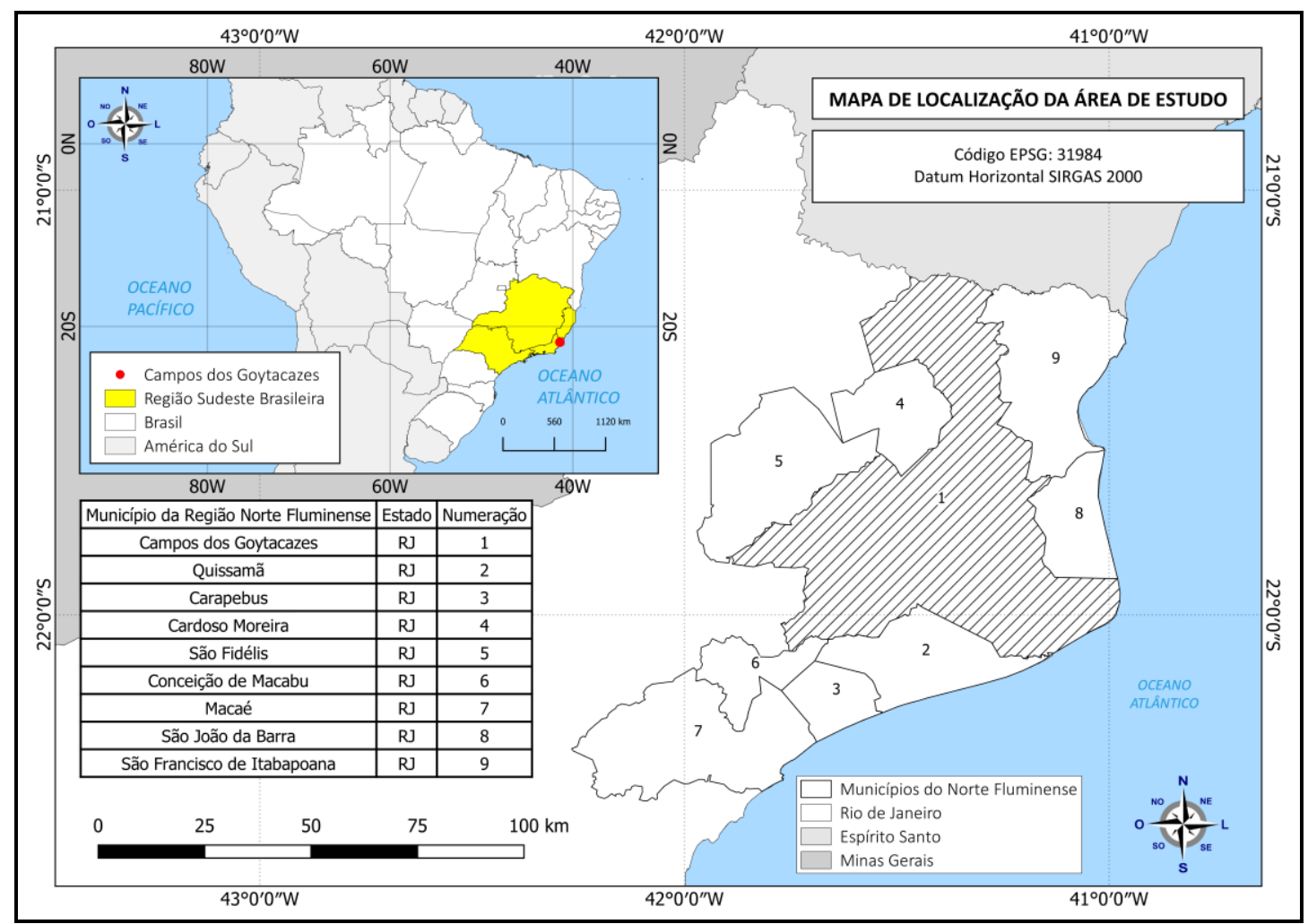

Fonte: Autores (2019).

Campos dos Goytacazes - RJ está inserido na Bacia Hidrográfica do Rio Paraíba do Sul, mais precisamente na Região Hidrográfica do Baixo Paraíba do Sul e Itabapoana, conhecida como Região Hidrográfica IX (CBH BPSI, 2019), abrangendo parte da planície costeira do rio Paraíba do Sul (Lämmle e Bulhões, 2019), situada ao norte do estado do Rio de janeiro, na região sudeste do Brasil. Apresenta uma área territorial correspondente a estabelecimentos agropecuários de 255.774,547 ha (aproximadamente 63,4\% de seu território) segundo o IBGE (2019). Desta, 3.113,030 ha são de lavouras permanentes, 31.519,126 ha são de lavouras temporárias, 143,474 ha são destinados a cultivos de flores, 184.171,139 ha são de pastagens, 839.399 ha são de matas ou florestas naturais, $18.566,985$ ha são de matas ou florestas destinadas à preservação permanente ou reserva legal, 419,535 ha são de florestas plantadas e 975,509 ha são de área cultivada com espécies florestais também usada para lavouras e pastejo por animais (IBGE, 2019).

Revista Cerrados, Montes Claros/MG, v. 18, n. 2, p. 69-99, jul./dez.-2020. 
BARBOSA, A. I. G.; REIS, C. H.; MENDONÇA, J. C.; LÄMMLE, L.

O uso de Sensoriamento Remoto para estimar área plantada de cana-de-açúcar em Campos dos Goytacazes - RJ, Brasil

\section{Levantamento de Dados Orbitais}

A escolha das imagens se deu por meio de critérios como presença de nuvens e nebulosidade inferior a $15 \%$ ou ausência total de nuvens sobre o município correspondente à área de estudo, com espaçamento temporal entre as imagens de modo a observar diferentes estágios de desenvolvimento vegetativo dos colmos da cana-de-açúcar, pois suas diferenças de altura geram resposta visual em tonalidades e cores distintas no âmbito das técnicas de interpretação visual. A Tabela 1 apresenta as datas das imagens escolhidas e utilizadas para a análise e interpretação visual dos talhões de cana-de-açúcar no município de Campos dos Goytacazes.

Tabela 1 - Imagens do sensor OLI do satélite LANDSAT-8 utilizadas

\begin{tabular}{ccccc}
\hline Imagem & Órbita & Ponto & Data & Ano-Safra \\
\hline $\mathbf{1}$ & 75 & 216 & $21 / 07 / 2017$ & $2017-2018$ \\
$\mathbf{2}$ & 75 & 216 & $09 / 10 / 2017$ & $2017-2018$ \\
$\mathbf{3}$ & 75 & 216 & $02 / 03 / 2018$ & $2017-2018$ \\
$\mathbf{4}$ & 75 & 216 & $08 / 07 / 2018$ & $2018-2019$ \\
\hline
\end{tabular}

Fonte: Autores (2019).

As imagens utilizadas foram adquiridas na plataforma eletrônica do INPE (Divisão de Geração de Imagens) no ano de 2019 e são provenientes do sensor OLI, a bordo do satélite LANDSAT-8, uma vez que tais imagens atenderam aos critérios de resolução a serem trabalhados neste trabalho. De acordo com o INPE (2019b), o satélite estadunidense LANDSAT-8 foi lançado em 11 de fevereiro de 2013 construído pela Orbital Sciences Corporation e até o presente momento fornece imagens de um mesmo ponto da superfície terrestre a cada 16 dias, tempo este que corresponde à sua resolução temporal. O LANDSAT8 conta com dois sensores, sendo eles: TIRS e OLI. Em consonância com o espectro eletromagnético, o segundo apresenta bandas espectrais correspondentes às faixas do espectro eletromagnético que variam de 0,433 $\mu \mathrm{m}$ a 1,390 $\mu \mathrm{m}$ (EMBRAPA, 2013).

O critério de escolha das quatro imagens embasou-se na busca de período similar entre as mesmas, de modo a tornar possível a observação do acompanhamento do ciclo de desenvolvimento da cana-de-açúcar, desde o seu plantio (solo exposto) ou corte (tendência a 
BARBOSA, A. I. G.; REIS, C. H.; MENDONÇA, J. C.; LÄMMLE, L.

O uso de Sensoriamento Remoto para estimar área plantada de cana-de-açúcar em Campos dos Goytacazes - RJ, Brasil

solo-exposto, visto que o broto da cana remanescente da cana-soca encontra-se muito rente ao solo e sem reflectância característica de vegetação). Nesta etapa, optou-se por escolher imagens entre o início da moagem da cana-de-açúcar no ano-safra 2017/2018, que ocorreu em 20/04/2017 e o início da moagem do ano subsequente, em 02/07/2018 (COAGRO, 2019), uma vez que neste intervalo ocorreu o ciclo completo de desenvolvimento, maturação e início da colheita da cana-de-açúcar.

Também foram adquiridos modelos digitais de elevação (MDE) provenientes do sensor Shuttle Radar Topography Mission (SRTM) que esteve acoplado ao ônibus espacial Endeavour em fevereiro de 2000, e do sensor Advanced Spaceborne Thermal Emission and Reflection Radiometer (ASTER) a bordo do satélite TERRA. De acordo com a National Aeronautics and Space Administration (NASA, 2019), o modelo digital de elevação global ASTER possui resolução espacial de aproximadamente 30 metros e foi produzido por meio de uma colaboração entre a NASA e o Japan's Ministry of Economy, Trade, and Industry (METI). Os modelos digitais de elevação foram adquiridos na plataforma do serviço geológico dos Estados Unidos (USGS) e o banco de dados foi criado através de imageamento obtido entre 01/03/2000 e 30/11/2013. Utilizou-se a combinação das bandas 4, 5 e 6 do sensor LANDSAT, cujas características estão descritas na Tabela 2:

Tabela 2 - Características do sensor OLI a bordo do satélite LANDSAT-8

\begin{tabular}{|c|c|c|c|c|c|}
\hline Bandas Espectrais & $\begin{array}{l}\text { Resolução } \\
\text { Espectral }\end{array}$ & $\begin{array}{l}\text { Resolução } \\
\text { Espacial }\end{array}$ & $\begin{array}{l}\text { Resolução } \\
\text { Temporal }\end{array}$ & $\begin{array}{c}\text { Área } \\
\text { Imageada }\end{array}$ & $\begin{array}{c}\text { Res. } \\
\text { Radiométrica }\end{array}$ \\
\hline (B1) COSTAL & $0.433-0.453 \mu \mathrm{m}$ & $30 \mathrm{~m}$ & \multirow{9}{*}{16 dias } & \multirow{9}{*}{$185 \mathrm{~km}$} & \multirow{9}{*}{12 bits } \\
\hline (B2) AZUL & $0.450-0.515 \mu \mathrm{m}$ & $30 \mathrm{~m}$ & & & \\
\hline (B3) VERDE & $0.525-0.600 \mu \mathrm{m}$ & $30 \mathrm{~m}$ & & & \\
\hline (B4) VERMELHO & $0.630-0.680 \mu \mathrm{m}$ & $30 \mathrm{~m}$ & & & \\
\hline $\begin{array}{l}\text { (B5) INFRAVERMELHO } \\
\text { PRÓXIMO }\end{array}$ & $0.845-0.885 \mu \mathrm{m}$ & $30 \mathrm{~m}$ & & & \\
\hline $\begin{array}{c}\text { (B6) INFRAVERMELHO } \\
\text { MÉDIO }\end{array}$ & $1.560-1.660 \mu \mathrm{m}$ & $30 \mathrm{~m}$ & & & \\
\hline $\begin{array}{c}\text { (B7) INFRAVERMELHO } \\
\text { MÉDIO }\end{array}$ & $2.100-2.300 \mu \mathrm{m}$ & $30 \mathrm{~m}$ & & & \\
\hline (B8) PANCROMÁTICO & $0.500-0.680 \mu \mathrm{m}$ & $15 \mathrm{~m}$ & & & \\
\hline (B9) Cirrus & $1.360-1.390 \mu \mathrm{m}$ & $30 \mathrm{~m}$ & & & \\
\hline
\end{tabular}

Fonte: EMBRAPA (2013). Adaptação: Autores (2019).

Revista Cerrados, Montes Claros/MG, v. 18, n. 2, p. 69-99, jul./dez.-2020. 
BARBOSA, A. I. G.; REIS, C. H.; MENDONÇA, J. C.; LÄMMLE, L.

O uso de Sensoriamento Remoto para estimar área plantada de cana-de-açúcar em Campos dos Goytacazes - RJ, Brasil

Tais bandas equivalem aos comprimentos de onda do espectro eletromagnético onde os valores de reflectância de folhas verdes sadias são maiores do que os de absortância. Sabe-se que a região espectral entre $700 \mathrm{~nm}$ e $1.300 \mathrm{~nm}$ apresenta altos valores de reflectância e baixos valores de absortância devido à composição da estrutura interna das folhas verdes sadias (FORMAGGIO e SANCHES, 2017).

Desta forma, as folhas refletem pouco na faixa do Visível porque absorvem grande parte da radiação na realização do procedimento de fotossíntese. $\mathrm{Na}$ faixa do Infravermelho de Ondas Longas (NIR), nota-se maior grau de reflectância devido à estrutura celular que permite a ocorrência de tal fenômeno. Por fim, os níveis de reflectância tornam a diminuir à medida que avançamos para a faixa do Infravermelho de Ondas Curtas (SWIR), que podem ser indicados para estimativa do conteúdo de água presente nas folhas, conforme podemos visualizar na Figura 3:

Figura 3 - Comportamento espectral da vegetação

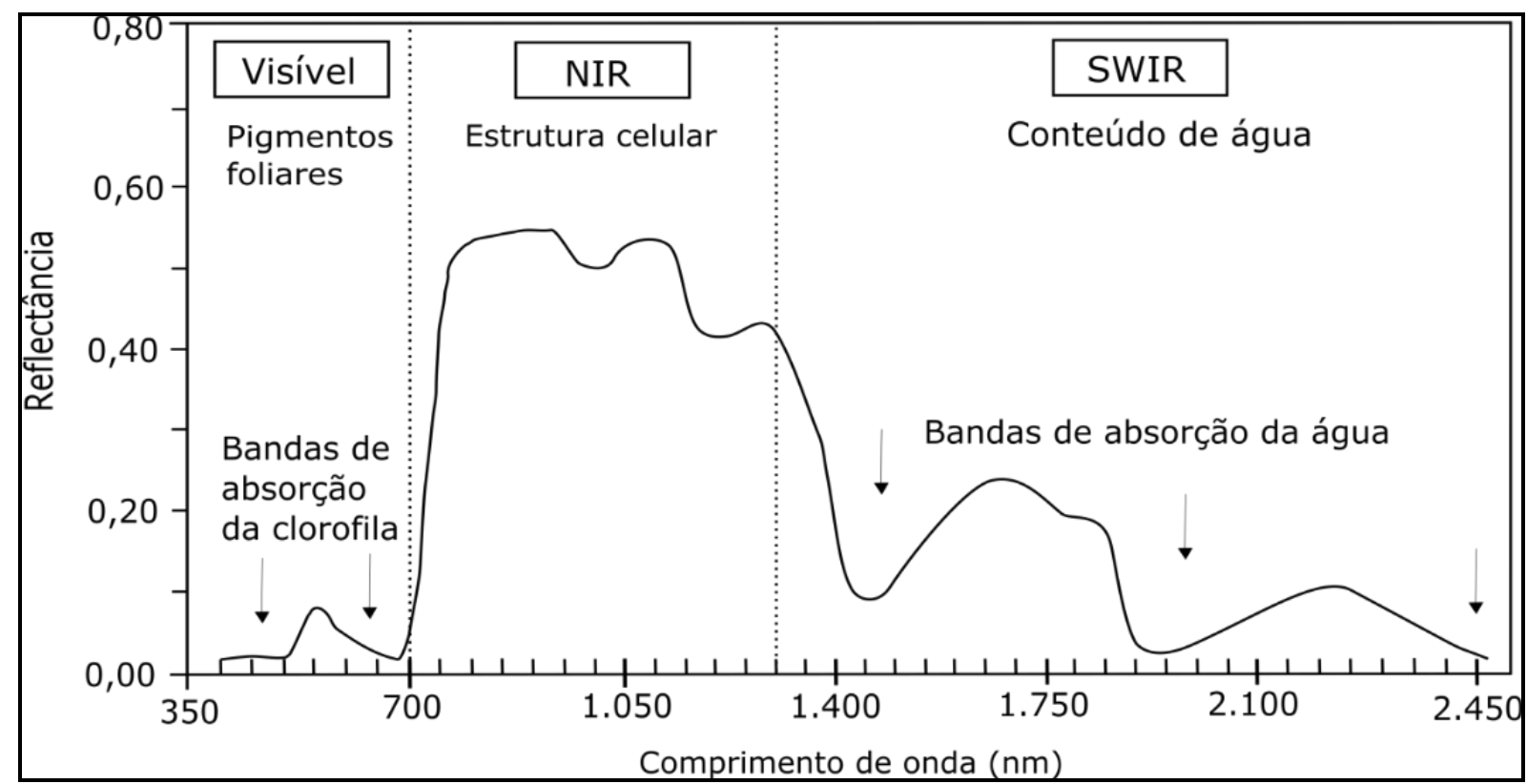

Fonte: Adaptado de Formaggio e Sanches (2017)

\section{Processamento Digital de Imagens}

O Processamento Digital de Imagens tem como principal objetivo fornecer ferramentas para facilitar identificação e extração de informações contidas nas imagens para 
BARBOSA, A. I. G.; REIS, C. H.; MENDONÇA, J. C.; LÄMMLE, L.

O uso de Sensoriamento Remoto para estimar área plantada de cana-de-açúcar em Campos dos Goytacazes - RJ, Brasil

posterior interpretação. O resultado desse processo é a produção de outras imagens que contenham informações específicas extraídas e realçadas a partir das imagens brutas. Softwares como o SPRING - INPE versão 5.5.5, que foi utilizado nesta pesquisa, são utilizados para atividades interativas de análise e manipulação das imagens brutas.

\section{Carregamento de Cena}

Uma vez que as imagens já haviam sido baixadas e descompactadas, puderam ser carregadas no software SPRING. O presente trabalho utilizou um banco de dados fornecido pelo Laboratório de Engenharia Agrícola (LEAG) da Universidade Estadual do Norte Fluminense Darcy Ribeiro (UENF), sendo os mesmos utilizados por Mendonça et al. (2011), tornando-se, desta forma, uma contribuição ao referido projeto, que foi executado na projeção UTM Datum WGS 84. Optou-se por não alterá-lo, pois o WGS 84 é um sistema de projeção geocêntrico e ainda muito utilizado para as coordenadas cartesianas de sistemas de navegação global por satélite (BIELENKI JÚNIOR e BARBASSA, 2012).

Trabalhou-se exclusivamente com a composição colorida R5, G6, B4 (banda 5 associada ao canal vermelho, banda 6 associada ao canal verde e banda 4 associada ao canal azul). Esta composição possibilita que a vegetação adquira coloração magenta quando se encontra em estágio de desenvolvimento médio ou elevado e na cor tendendo para tons de esverdeados quando encontra-se rasteira. Selecionou-se as imagens referentes às bandas 5, $6 \mathrm{e}$ 4 das quatro datas mencionadas anteriormente, somando um total de 12 imagens nomeadas seguindo a seguinte lógica: satélite_sensor_data_banda.

\section{Ampliação Linear de Contraste}

A Ampliação Linear de Contraste foi a técnica adotada que consiste em "expandir a distribuição dos pixels originais (concentrados em um pequeno intervalo) para todo o intervalo possível, por exemplo, para 255 níveis em imagens de 8 bits, o que aumenta o contraste da imagem" (FLORENZANO, 2011, p. 10). Este exemplo é demonstrado na Figura 4: 


\section{BARBOSA, A. I. G.; REIS, C. H.; MENDONÇA, J. C.; LÄMMLE, L.}

O uso de Sensoriamento Remoto para estimar área plantada de cana-de-açúcar em Campos dos Goytacazes - RJ, Brasil

Figura 4 - Realce por ampliação linear de contraste
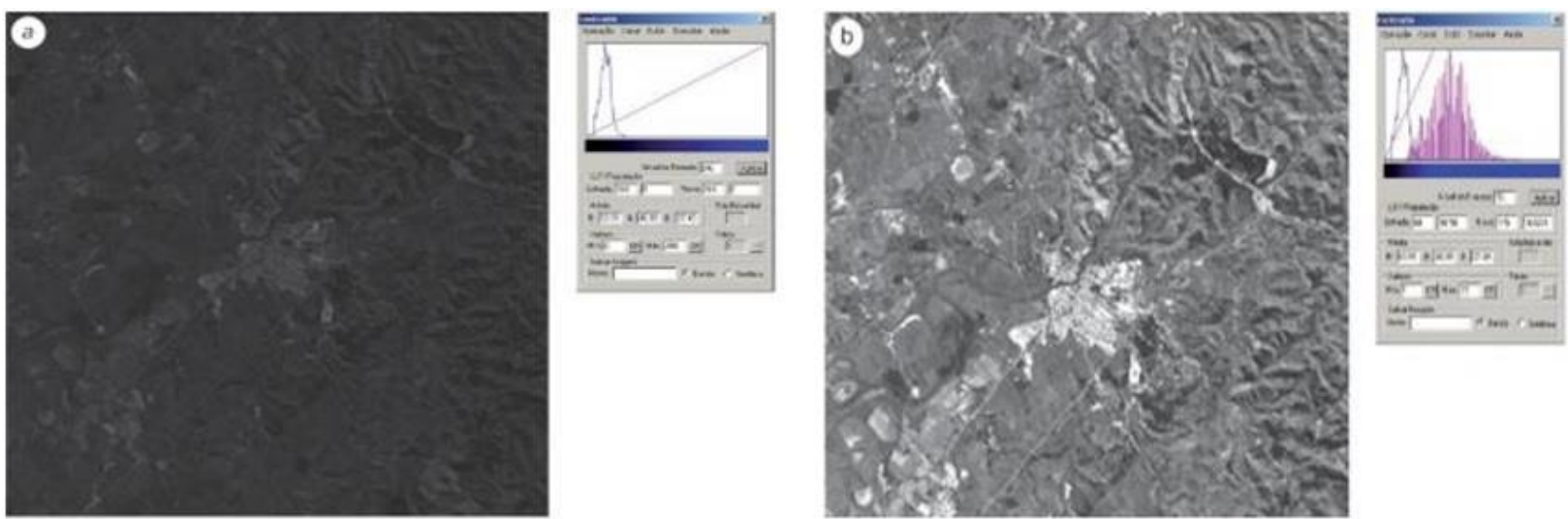

Fonte: Florenzano (2011). Adaptação: Autores (2020)

As imagens carregadas no software SPRING já estavam georreferenciadas, mas não contrastadas. Por isso, realizou-se o procedimento de contraste selecionando-as uma a uma. Atribuiu-se um nome para que fosse gerado um novo Plano de Informação (PI) mantendo os nomes originais das imagens e somente acrescentando "_contraste" à frente dos nomes (para critério de organização das informações). A Figura 5 apresenta um comparativo de uma imagem carregada no software antes e após o procedimento de realização do contraste:

Figura 5 - Antes e depois da aplicação de contraste

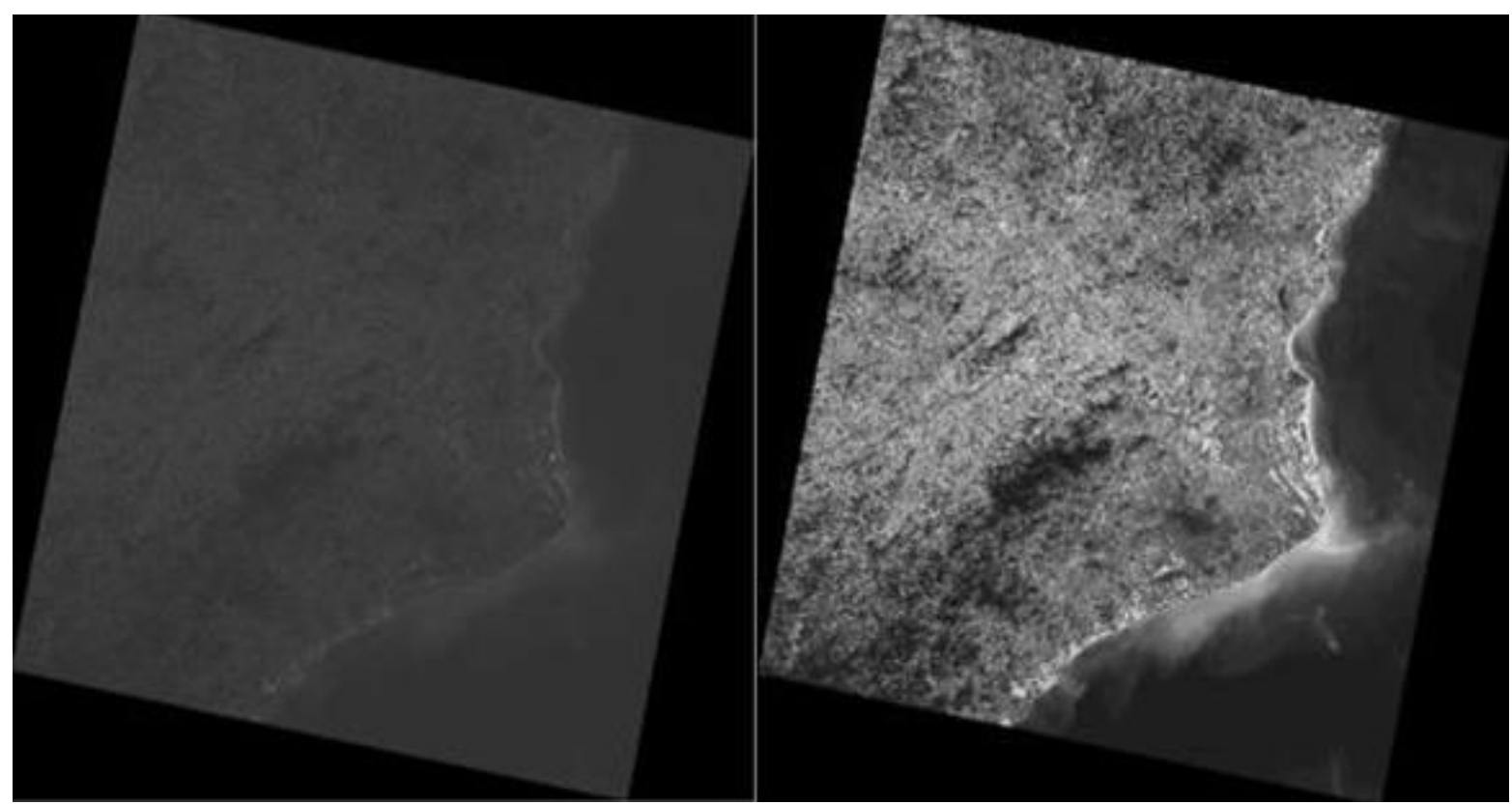

Fonte:Autores (2019). 
BARBOSA, A. I. G.; REIS, C. H.; MENDONÇA, J. C.; LÄMMLE, L.

O uso de Sensoriamento Remoto para estimar área plantada de cana-de-açúcar em Campos dos Goytacazes - RJ, Brasil

\section{Delimitação e Exclusão de Áreas}

Tal procedimento reduziu o tamanho das imagens originais de forma a abranger apenas o recorte municipal, transformando-as em imagens com quantidade de pixels suficiente para preencher a área do município em questão, concomitantemente otimizando o tempo de execução dos processamentos realizados nas futuras operações no software. A Figura 6 exibe um comparativo entre o tamanho das imagens originais e a redução do quantitativo de pixels nas recém geradas imagens após o recorte do PI.

Figura 6 - Comparativo do antes e depois do Recorte do PI

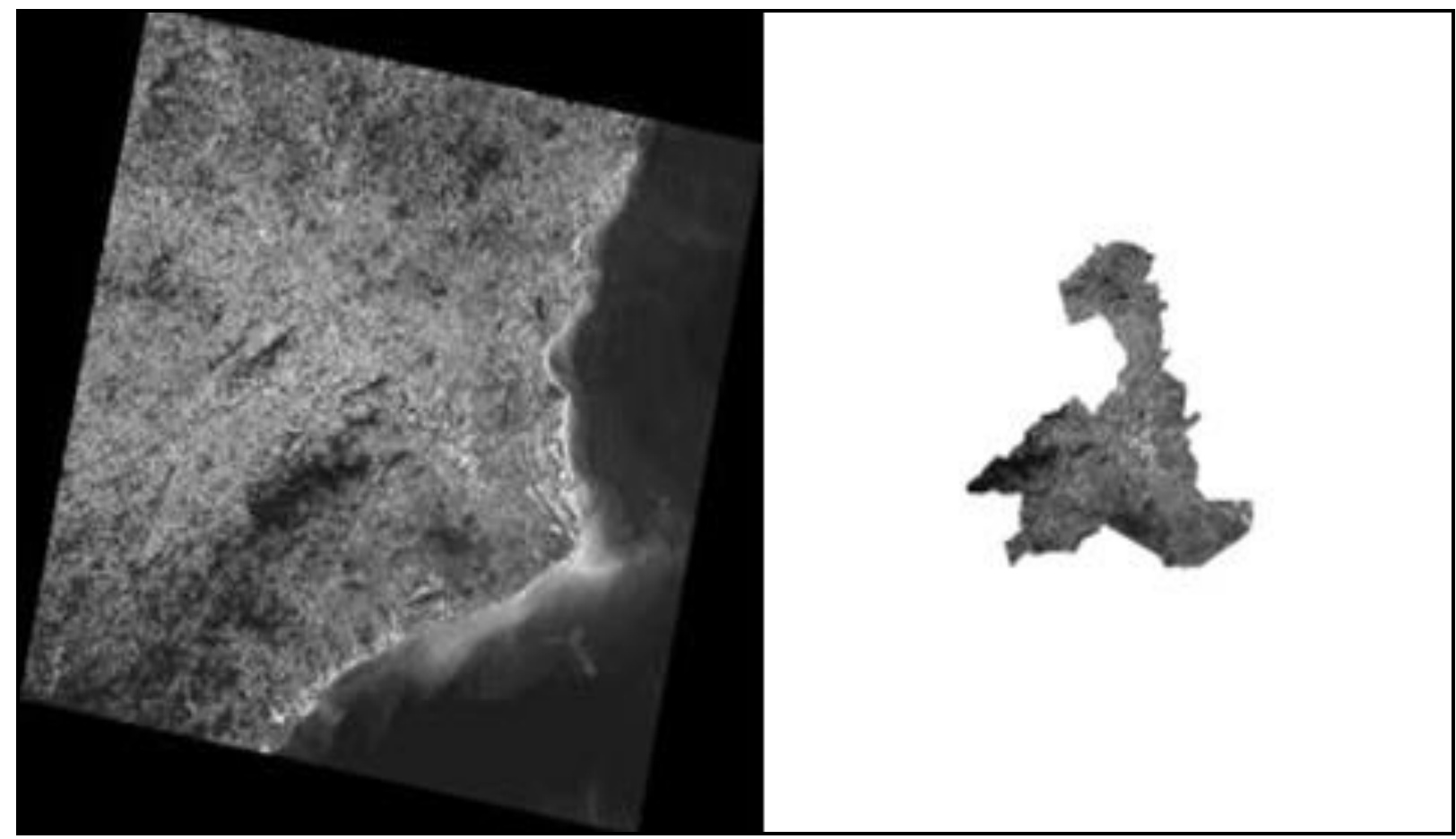

Fonte: Autores (2019).

O próximo passo foi a realização da composição colorida RGB de acordo com o critério abordado anteriormente. Para realizar este procedimento bastou clicar nas imagens e associá-las às bandas dentro do próprio plano de informação. A composição colorida das imagens é exibida no mosaico correspondente à composição da Figura 7: 
BARBOSA, A. I. G.; REIS, C. H.; MENDONÇA, J. C.; LÄMMLE, L.

O uso de Sensoriamento Remoto para estimar área plantada de cana-de-açúcar em Campos dos Goytacazes - RJ, Brasil

Figura 7 - Comparativo das quatro imagens em composição colorida

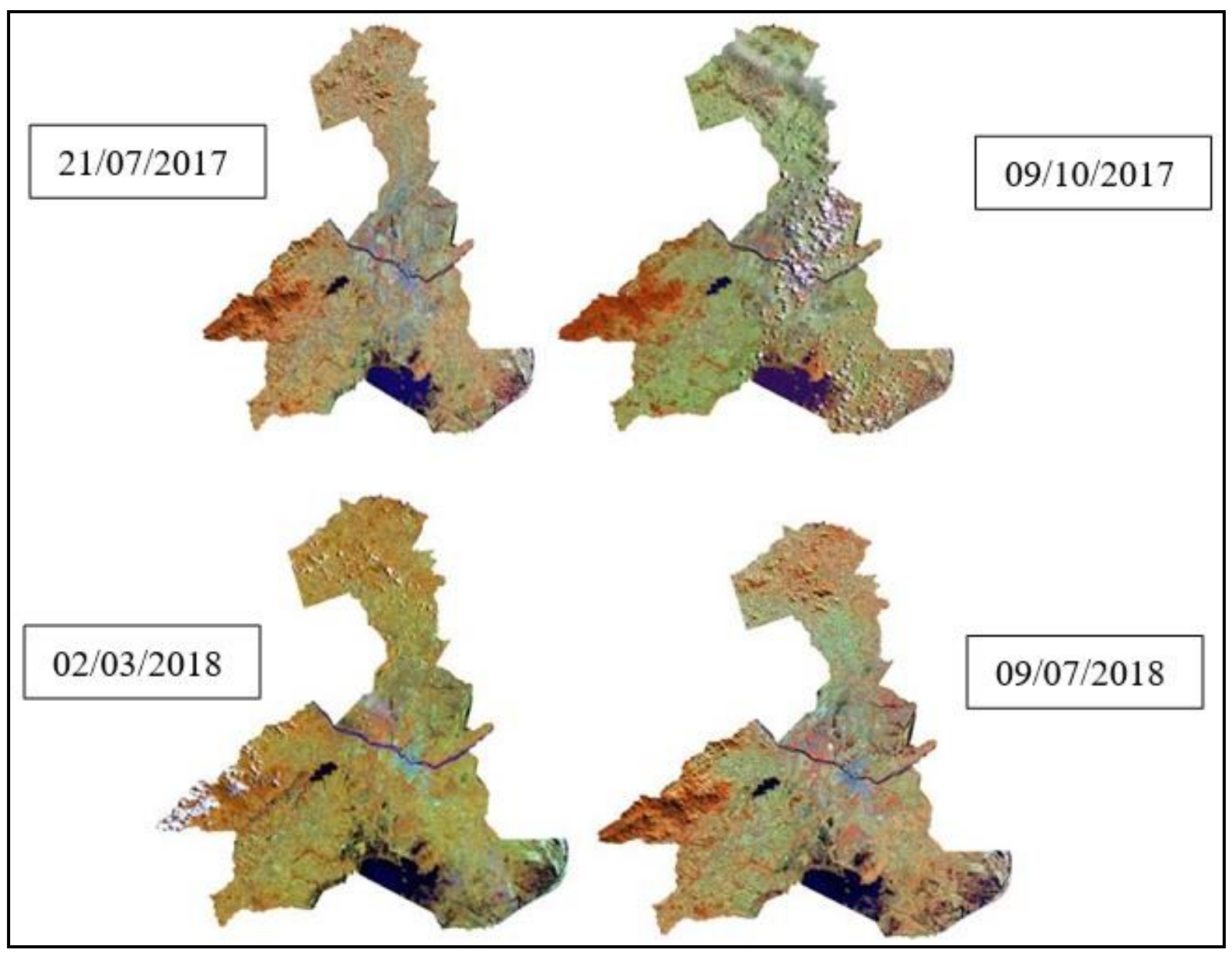

Fonte: Autores (2019).

\section{Interpretação Visual dos Polígonos}

A delimitação dos polígonos referentes às áreas de plantio da cana-de-açúcar foi feita por meio da associação visual destas conforme determinada reflectância a partir da seleção de bandas. De acordo com a composição utilizada (bandas R5, G6, B4) áreas de solo exposto apresentavam uma tonalidade esbranquiçada ou levemente azulada, enquanto áreas de cana em pé apresentavam uma tonalidade avermelhada não muito escura (magenta). A delimitação dos polígonos referentes às áreas de plantio da cana-de-açúcar foi feita por meio da associação visual destas áreas de acordo com um determinado padrão de cores refletidas a partir da seleção das bandas, sendo possível gerar uma chave de interpretação conforme demonstração na Figura 8: 
BARBOSA, A. I. G.; REIS, C. H.; MENDONÇA, J. C.; LÄMMLE, L.

O uso de Sensoriamento Remoto para estimar área plantada de cana-de-açúcar em Campos dos Goytacazes - RJ, Brasil

Figura 8 - Chave de interpretação com base no diferencial das cores

Paleta de cores de áreas referentes à solo exposto na composição RGB 564

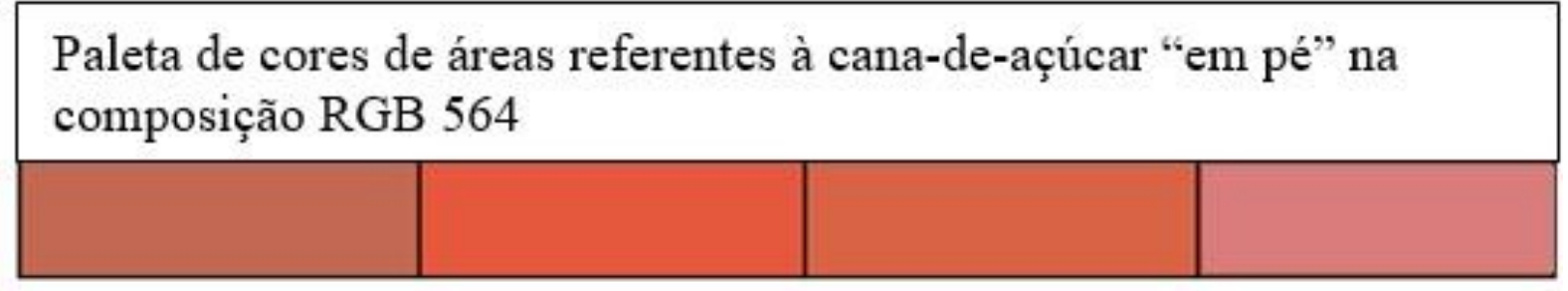

Fonte: Autores, (2020).

Em algumas ocasiões não houve contraste entre os alvos no que se refere aos padrões de cores referentes à reflectância, o que gerou confusões interpretativas. Em tais casos, utilizou-se o software Google Earth Pro® em sua função "Mostrar imagens históricas" no período correspondente ao da análise feita no presente trabalho, visualizando-as sobre as mesmas coordenadas correspondentes aos pontos que geravam dúvida de interpretação ao analisar as imagens geradas pelo OLI. Apesar do Google Earth Pro ${ }^{\circledR}$ apresentar imagens nas cores visíveis pelo olho humano, apresentam resolução espacial superior à apresentada pelas imagens captadas pelo OLI. Na composição colorida, as imagens do Google Earth Pro ® apresentavam área ocupada com cana-de-açúcar com as características apresentadas na Figura 9. Em tais ocasiões, a rugosidade, o arranjo dos talhões e o nível de coloração esverdeada da vegetação permitia ao fotointérprete identificar a área como sendo ou não ocupada por canade-açúcar no período observado.

A Figura 10 apresenta o demonstrativo da vetorização dos polígonos referentes às áreas de plantio de cana-de-açúcar com base na interpretação visual através do padrão de cores: 
BARBOSA, A. I. G.; REIS, C. H.; MENDONÇA, J. C.; LÄMMLE, L.

O uso de Sensoriamento Remoto para estimar área plantada de cana-de-açúcar em Campos dos Goytacazes - RJ, Brasil

Figura 9 - Exemplo de visualização no Google Earth Pro

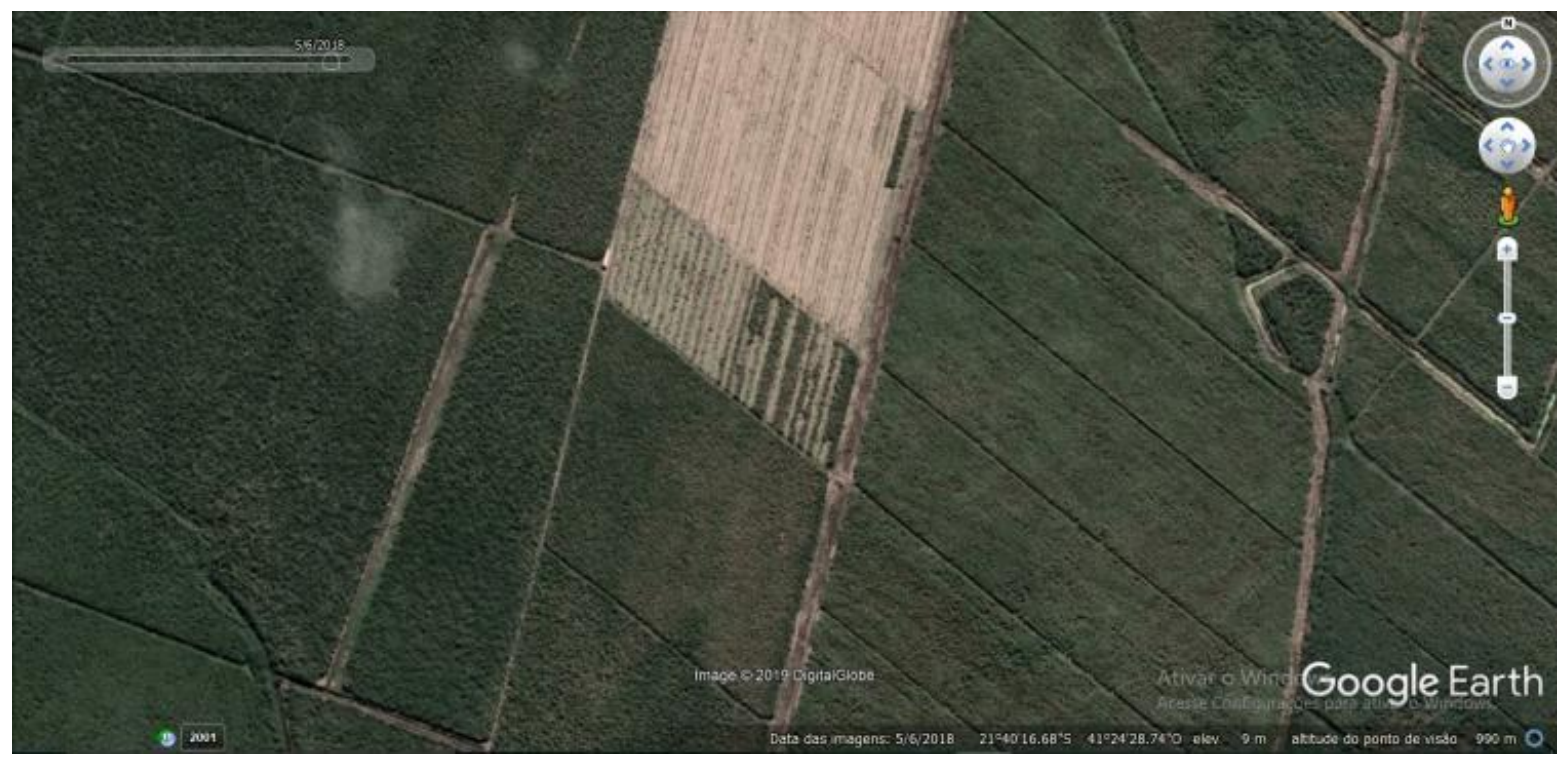

Fonte: Autores (2019).

Figura 10 - Exemplo da criação do PI para vetorização das áreas de cana-de-açúcar

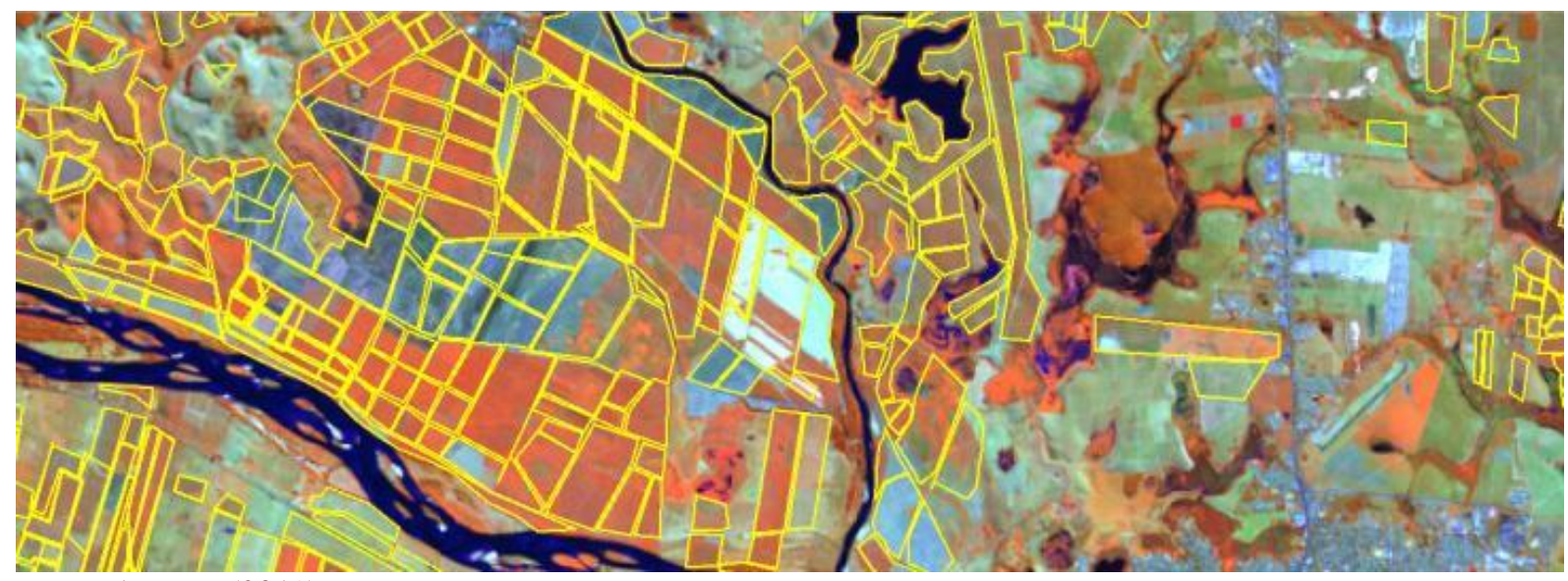

Fonte: Autores (2019).

Uma vez elaborada a demarcação dos polígonos referentes ao objeto de estudo, foi preciso criar uma categoria nomeando-a com o objeto de estudo e associá-los a esta categoria, para que o algoritmo do software pudesse correlacionar a que classe pertence o polígono previamente demarcado. O número de classes depende do que se quer analisar (no caso de classificações supervisionadas). Em mapeamento do uso do solo é comum haver associação de classes como: água, solo exposto, pastagem/cultura (podendo ser diferenciado o tipo de cultura), vegetação nativa, dentre outras (FLORENZANO, 2011). 
BARBOSA, A. I. G.; REIS, C. H.; MENDONÇA, J. C.; LÄMMLE, L.

O uso de Sensoriamento Remoto para estimar área plantada de cana-de-açúcar em Campos dos Goytacazes - RJ, Brasil

\section{Obtenção da declividade do terreno}

A obtenção da declividade do terreno foi realizada através dos dados disponibilizados pelos modelos digitais de elevação (MDE) ASTER, SRTM e TOPODATA. Foi realizada a importação das grades altimétricas referentes aos MDE recém-baixados para a interface do software utilizado. Dando sequência, realizou-se o mosaico das grades/imagens de declividade recém-carregadas para que cobrissem a área referente ao município de Campos dos Goytacazes. Extraiu-se o recorte das grades/imagens de declividade referente ao contorno do município de Campos dos Goytacazes.

O objetivo foi gerar dois mapas de declividade do município de Campos dos Goytacazes para cada MDE, cujo primeiro apresentasse a classificação da Embrapa (2006) para as classes de declividade (subdividindo o relevo em plano, suave ondulado, ondulado, forte ondulado, montanhoso e escarpado) enquanto o segundo apresentasse somente duas classes em prol da análise referente à Lei Estadual no 5.990 de 20 de junho de 2011 (RIO DE JANEIRO, 2011), identificando desta forma áreas onde predominam até $12 \%$ de declividade e áreas em que seu percentual encontra-se acima deste valor.

A etapa seguinte foi a observância da análise exploratória dos dados estatísticos referentes à matriz do PI do mosaico dos dados de declividade referente ao município de Campos dos Goytacazes - RJ. Sendo assim, criou-se uma classe temática de acordo com a classificação de declividade feita pela Embrapa (2006), cujos intervalos adotados foram: de $0 \%$ a $3 \%$; de $3 \%$ a $8 \%$; de $8 \%$ a $20 \%$; de $20 \%$ a $45 \%$; de $45 \%$ a $75 \%$; e, por fim, maiores que $75 \%$.

O procedimento seguinte foi associar as cores para cada classe em "Visual". Os valores exibidos no Relatório de Dados foram transformados em porcentagem para que as classes temáticas pudessem ser exibidas, primeiramente, de acordo com a classificação Embrapa (2006).

\section{Cruzamento dos dados}

Esta etapa consistiu em programar o software para que ele retornasse os valores referentes à análise estatística exploratória da área ocupada por cana-de-açúcar inserida em 
BARBOSA, A. I. G.; REIS, C. H.; MENDONÇA, J. C.; LÄMMLE, L.

O uso de Sensoriamento Remoto para estimar área plantada de cana-de-açúcar em Campos dos Goytacazes - RJ, Brasil

áreas com declividade maiores ou iguais a 12\%. Tais são as áreas em que seria permitida a queima da palha da cana-de-açúcar no período da colheita, devido à dificuldade de alocação dos maquinários responsáveis por realizar a colheita. Para a realização de tal procedimento, utilizou-se a Linguagem Espacial para Geoprocessamento Algébrico (LEGAL), um algoritmo disponibilizado no software SPRING. A Figura 11 exibe como exemplo o procedimento feito com o MDE TOPODATA, sendo o mesmo também realizado nos MDE ASTER e SRTM.

Figura 11 - Sintaxe do algoritmo LEGAL para análise de áreas de declividade >=12\%

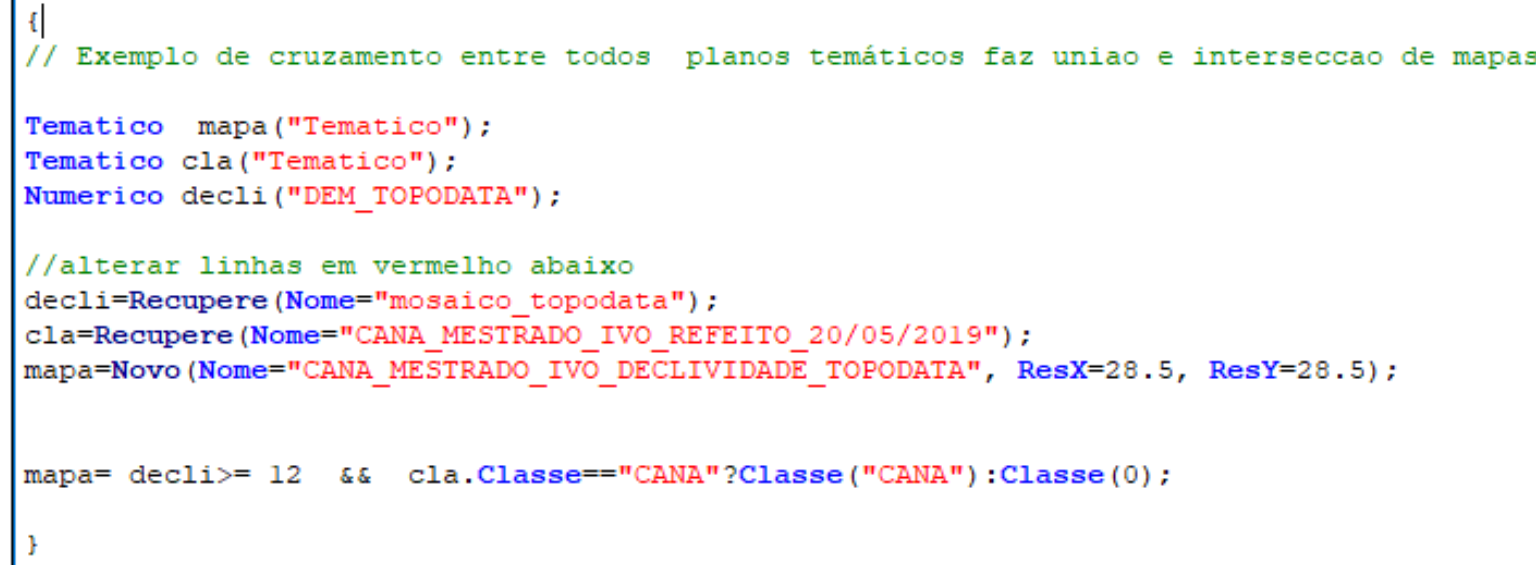

Fonte: Autores (2019).

\section{RESULTADOS E DISCUSSÃO}

O cálculo de medida de classes apontou uma área plantada de cana-de-açúcar no ano-safra 2017/2018 de 25.238,34 ha. Como o município possui uma extensão territorial de 403.248,7 ha, a área ocupada com o cultivo da cana-de-açúcar para o respectivo ano-safra equivale a aproximadamente $6,26 \%$ de sua extensão territorial.

A Figura 12 exibe o mapa que apresenta a área de estudo na composição RGB 5, 6 e 4; bem como a classe de uso do solo cana-de-açúcar referente ao ano-safra 2017/2018. 
BARBOSA, A. I. G.; REIS, C. H.; MENDONÇA, J. C.; LÄMMLE, L.

O uso de Sensoriamento Remoto para estimar área plantada de cana-de-açúcar em Campos dos Goytacazes - RJ, Brasil

Figura 12 - Área plantada de cana-de-açúcar em Campos dos Goytacazes (2017/2018) por meio da IVP

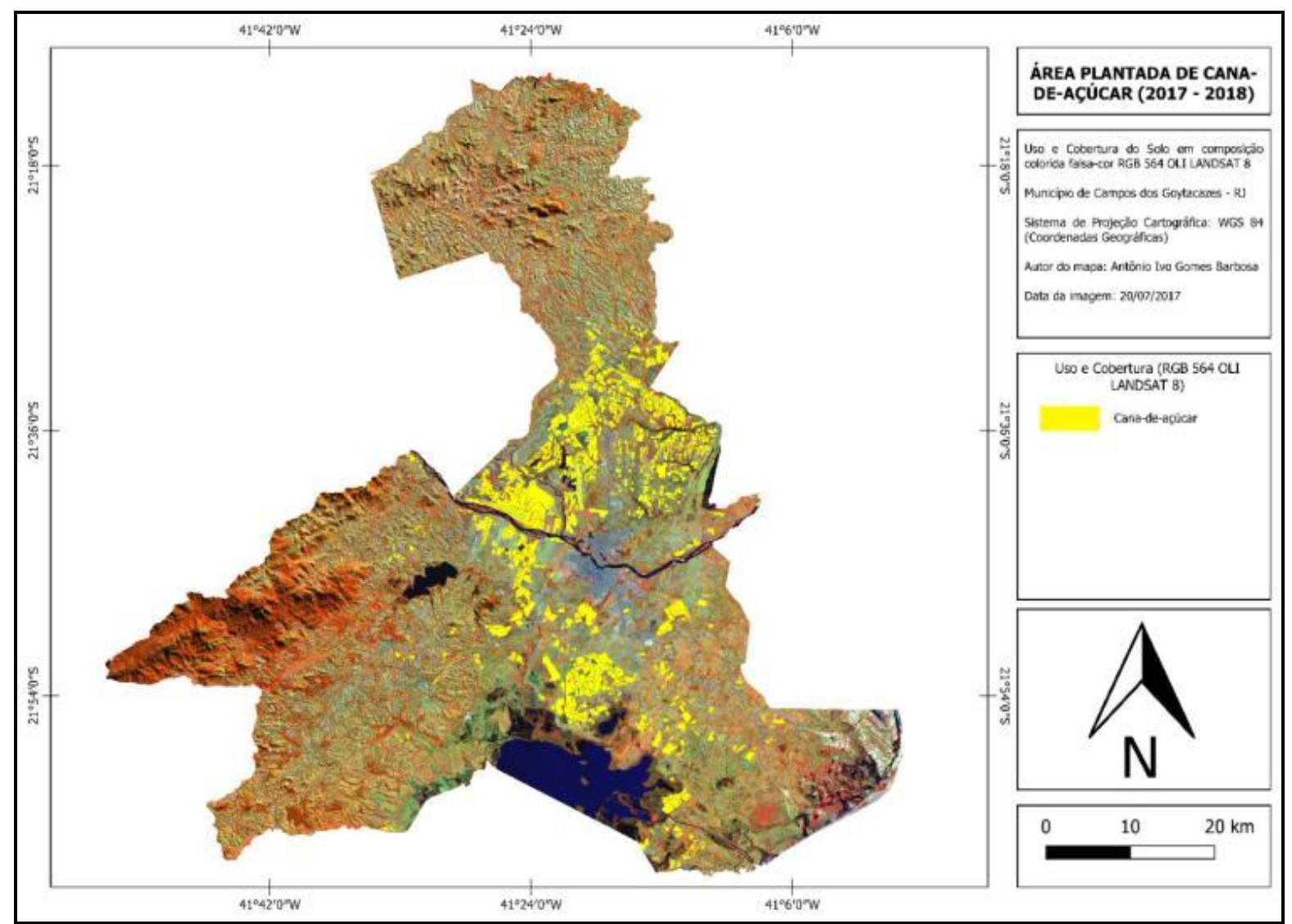

Fonte: Autores (2019).

Os resultados para os valores de declividade do território do município de Campos dos Goytacazes segundo Embrapa (2006), estão apresentados em valores unitários (ha) de acordo com os MDE TOPODATA, SRTM e ASTER na Tabela 3. Destaca-se que os valores percentuais presentes nesta tabela foram obtidos com base na dimensão territorial do município de Campos dos Goytacazes apresentada pelo IBGE (403.248,7 ha), motivo pelo qual optou-se por ressaltar que tais valores devem ser interpretados como aproximados $(\sim)$.

Os mapas referentes às Figuras 13, 14 e 15 exibem os valores de declividade encontrados no município de Campos dos Goytacazes de acordo com os MDE mencionados previamente na Tabela 2. A Figura 13 exibe os valores de declividade encontrados no município de Campos dos Goytacazes de acordo com o MDE TOPODATA. Observam-se maiores rugosidades e declividades do terreno nas porções norte e oeste do município, fato que corrobora com a realidade. 
BARBOSA, A. I. G.; REIS, C. H.; MENDONÇA, J. C.; LÄMMLE, L.

O uso de Sensoriamento Remoto para estimar área plantada de cana-de-açúcar em Campos dos Goytacazes - RJ, Brasil

Tabela 3 - Resultados de valores de declividade dos MDE TOPODATA, SRTM e ASTER

\begin{tabular}{|c|c|c|c|c|c|c|c|}
\hline $\begin{array}{c}\text { Classe de } \\
\text { Declividade } \\
\text { (EMBRAPA, } \\
\text { 2006) }\end{array}$ & $\begin{array}{c}\text { Valor } \\
\text { unitário (ha) } \\
\text { TOPODATA }\end{array}$ & $\begin{array}{c}\% \text { em } \\
\text { relação a } \\
\text { área do } \\
\text { município }\end{array}$ & $\begin{array}{c}\text { Valor } \\
\text { unitário } \\
\text { (ha) } \\
\text { SRTM }\end{array}$ & $\begin{array}{c}\text { \% em } \\
\text { relação a } \\
\text { área do } \\
\text { município }\end{array}$ & $\begin{array}{c}\text { Valor } \\
\text { unitário } \\
\text { (ha) } \\
\text { ASTER }\end{array}$ & $\begin{array}{c}\text { \% em } \\
\text { relação ao } \\
\text { território } \\
\text { do } \\
\text { município }\end{array}$ & $\begin{array}{c}\text { Maior } \\
\text { diferença } \\
\text { (ha) }\end{array}$ \\
\hline $0 \%$ a $3 \%$ & $273.906,04$ & $\sim 67,93 \%$ & $283.259,41$ & $\sim 70,25 \%$ & $262.987,74$ & $\sim 65,22 \%$ & $20.271,67$ \\
\hline $3 \%$ a $8 \%$ & $88.217,8$ & $\sim 21,88 \%$ & $75.862,45$ & $\sim 18,81 \%$ & $96.389,91$ & $\sim 23,90 \%$ & $20.527,46$ \\
\hline $8 \%$ a $20 \%$ & $37.707,53$ & $\sim 9,35 \%$ & $34.941,22$ & $\sim 8,67 \%$ & $40.885,38$ & $\sim 10,14 \%$ & $5.944,16$ \\
\hline $20 \%$ a $45 \%$ & $3.098,30$ & $\sim 0,77 \%$ & $4.567,84$ & $\sim 1,13 \%$ & $2.687,23$ & $\sim 0,67 \%$ & $1.880,61$ \\
\hline $45 \%$ a $75 \%$ & 114,84 & $\sim 0,03 \%$ & 131,67 & $\sim 0,03 \%$ & 93,04 & $\sim 0,02 \%$ & 38,63 \\
\hline$>75 \%$ & 5,64 & $\sim<0,00 \%$ & 14,63 & $\sim<0,00 \%$ & 2,58 & $\sim<0,00 \%$ & 12,05 \\
\hline
\end{tabular}

Fonte: Autores (2019).

Figura 13 - Classes de Declividade (Embrapa, 2006) em Campos dos Goytacazes segundo o MDE TOPODATA

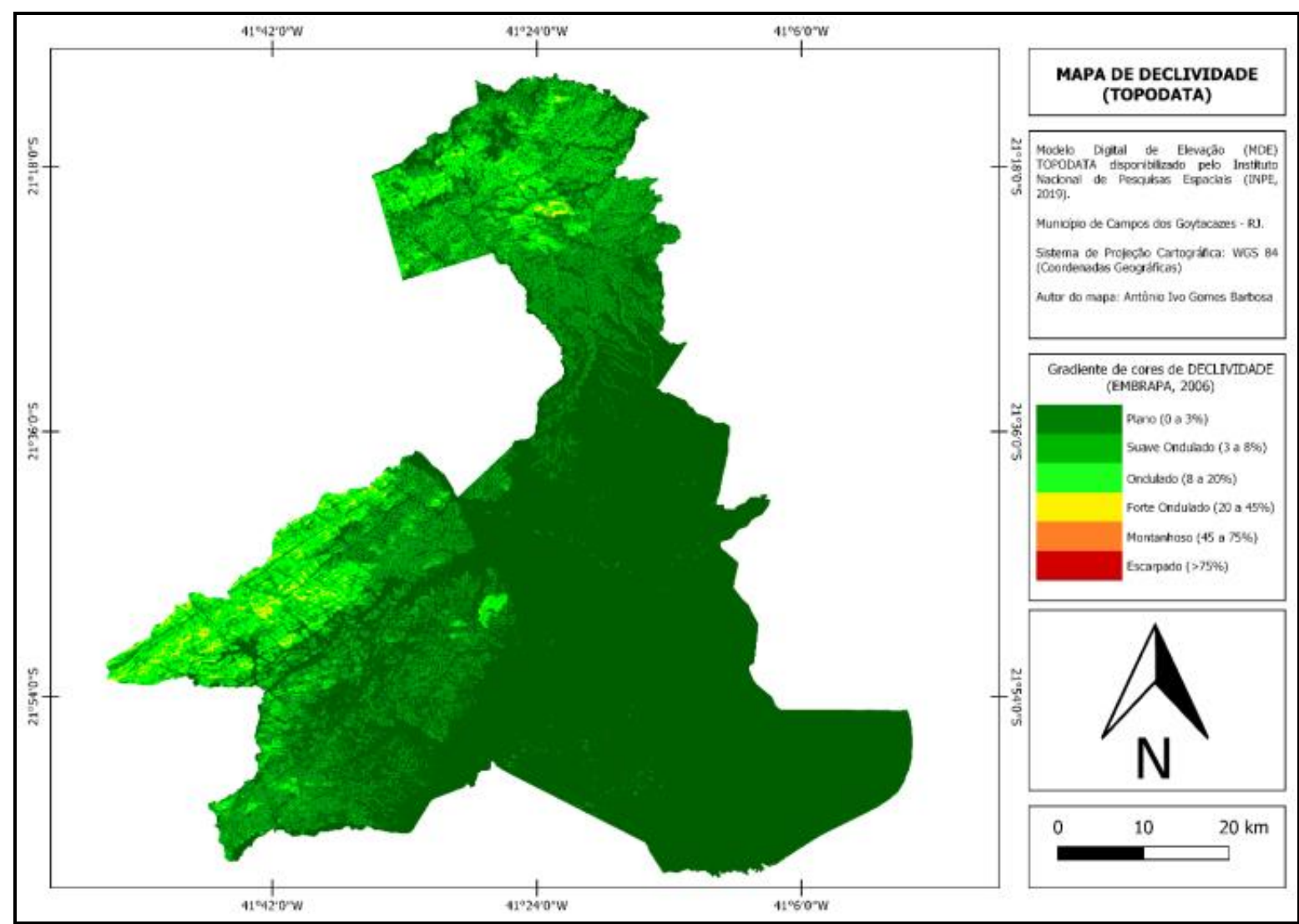

Fonte: Autores (2019).

Revista Cerrados, Montes Claros/MG, v. 18, n. 2, p. 69-99, jul./dez.-2020. 
BARBOSA, A. I. G.; REIS, C. H.; MENDONÇA, J. C.; LÄMMLE, L.

O uso de Sensoriamento Remoto para estimar área plantada de cana-de-açúcar em Campos dos Goytacazes - RJ, Brasil

A Figura 14 exibe os valores de declividade de acordo com o MDE SRTM. Assim como o resultado apresentado com base no MDE TOPODATA, também é possível observar maiores rugosidades e valores de declividade do terreno nas porções norte e oeste.

Figura 14 - Classes de Declividade (Embrapa, 2006) em Campos dos Goytacazes segundo o

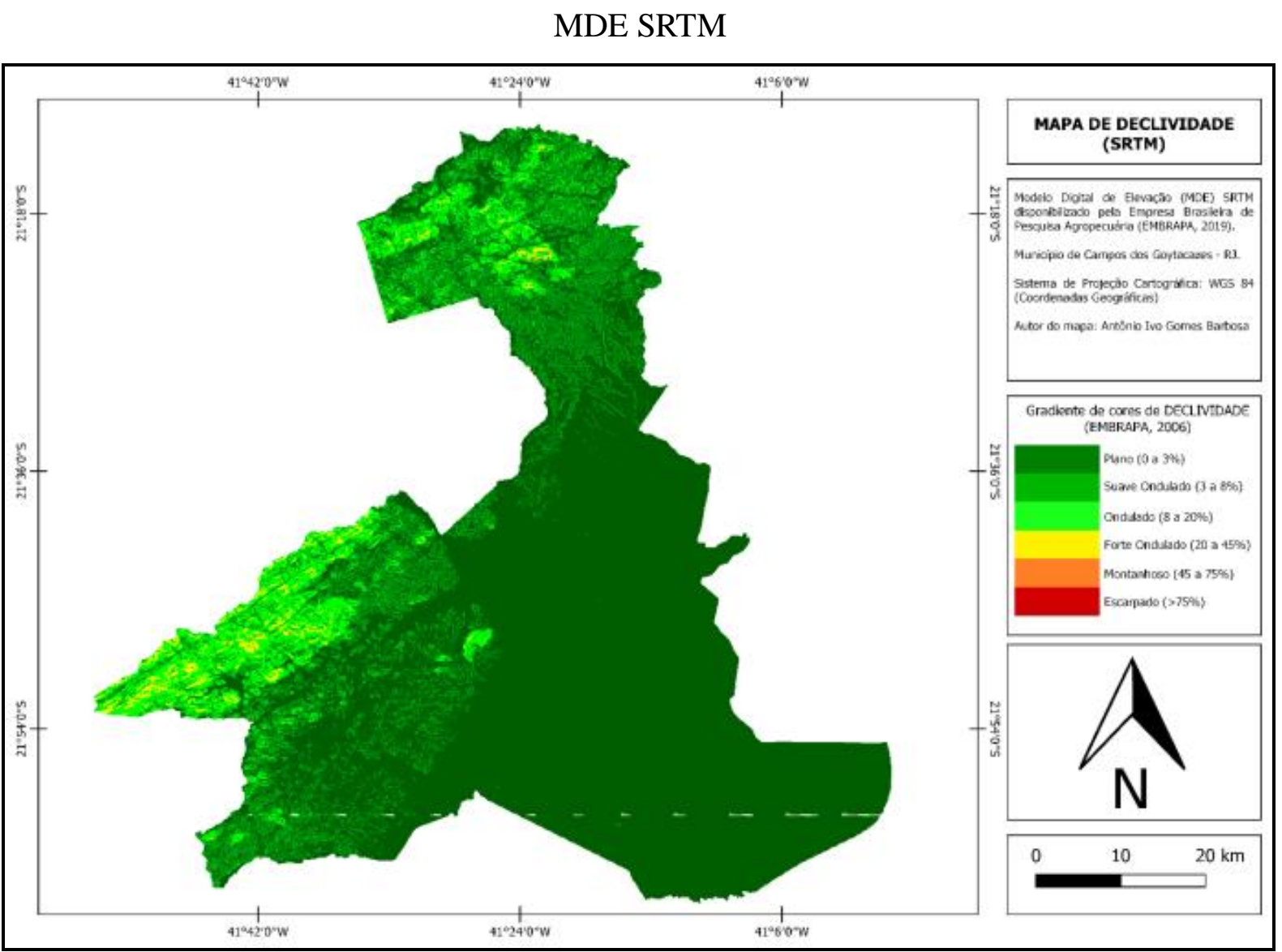

Fonte: Autores (2019).

A Figura 15 exibe os valores de declividade encontrados de acordo com o MDE ASTER. É possível observar rugosidades e declividades do terreno nas porções norte e oeste do município, fato este condizente com a realidade, mas ao contrário dos demais, também é possível observar uma espécie de "ruído" representativo de rugosidade e declividade do terreno nas demais áreas do território municipal, fato este não condizente com a realidade, uma vez que em tais áreas correspondem a territórios de baixada ou de declividades ínfimas não apresentáveis na escala adotada no produto gerado. 
BARBOSA, A. I. G.; REIS, C. H.; MENDONÇA, J. C.; LÄMMLE, L.

O uso de Sensoriamento Remoto para estimar área plantada de cana-de-açúcar em Campos dos Goytacazes - RJ, Brasil

Figura 15 - Classes de Declividade (Embrapa, 2006) em Campos dos Goytacazes segundo o MDE ASTER

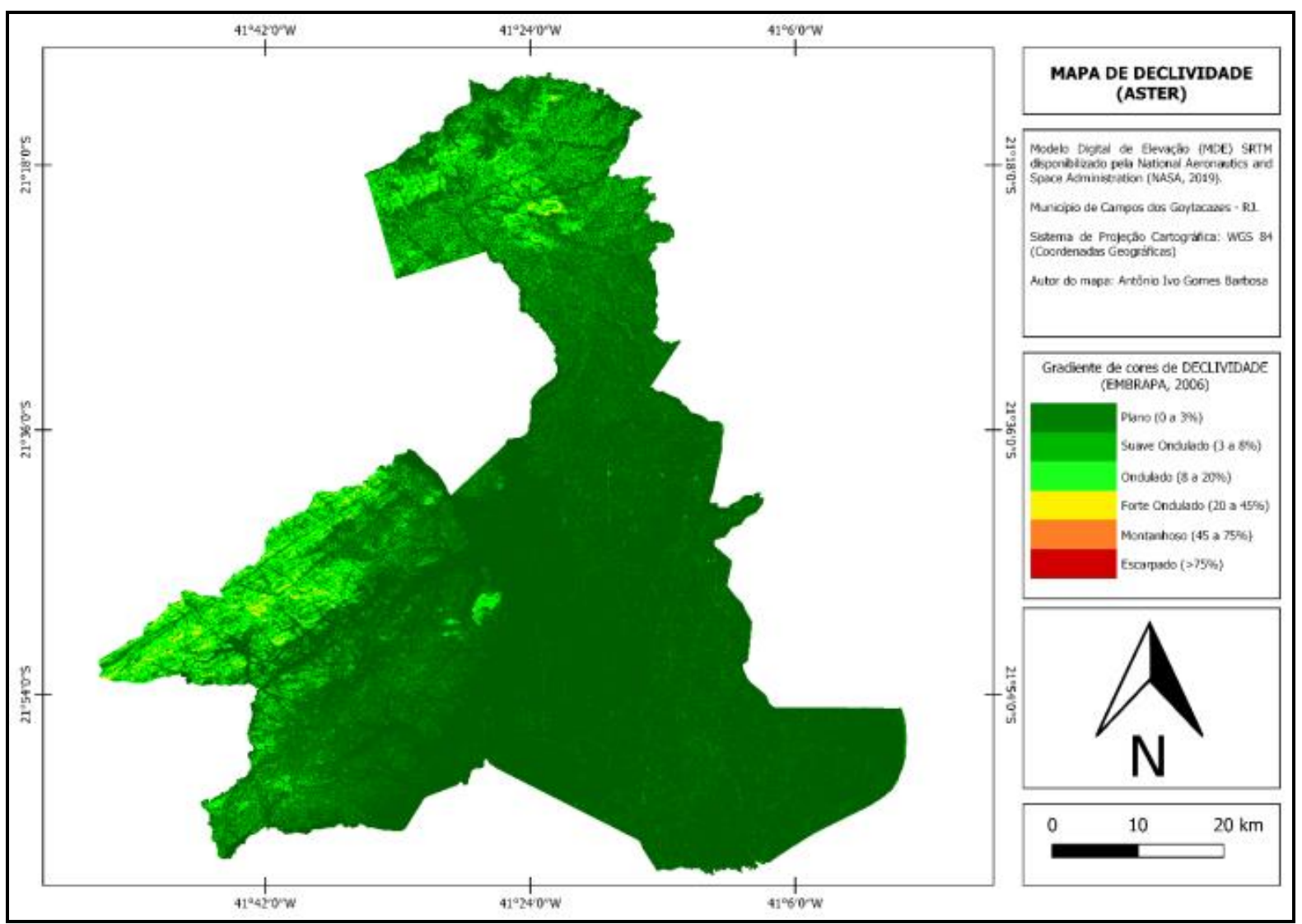

Fonte: Autores (2019).

A Tabela 4 apresenta os resultados da declividade territorial para os MDE TOPODATA, SRTM e ASTER sobre o município de Campos dos Goytacazes - RJ de acordo com os critérios da Lei Estadual no 5.990 de 20 de junho de 2011 (RIO DE JANEIRO, 2011). Portanto, tais resultados têm como objetivo apresentar os valores de extensão territorial total com declividades abaixo e acima de $12 \%$ e, deste modo, identificar a área ocupada pelo plantio da cana-de-açúcar onde seja permitida a queima da palha da cana. 
BARBOSA, A. I. G.; REIS, C. H.; MENDONÇA, J. C.; LÄMMLE, L.

O uso de Sensoriamento Remoto para estimar área plantada de cana-de-açúcar em Campos dos Goytacazes - RJ, Brasil

Tabela 4 - Resultados de valores de declividade total segundo a Lei Estadual n ${ }^{\circ} 5.990$ de 20 de junho de 2011

\begin{tabular}{ccc}
\hline MDE & Classe de Declividade & Valor unitário (ha) \\
\hline \multirow{2}{*}{ TOPODATA } & $0 \%$ a $12 \%$ & $385.873,94$ \\
\multirow{2}{*}{ SRTM } & $>12 \%$ & 17.176 .2 \\
& $0 \%$ a $12 \%$ & $378.676,31$ \\
ASTER & $>12 \%$ & $20.100,90$ \\
& $0 \%$ a $12 \%$ & $386.815,09$ \\
\end{tabular}

Fonte: Autores (2019).

A Tabela 5 exibe o resultado dos valores de declividade da área plantada de canade-açúcar no município de Campos dos Goytacazes - RJ segundo os parâmetros elencados pela Lei Estadual nº 5.990 de 20 de junho de 2011 (RIO DE JANEIRO, 2011).

Tabela 5 - Resultados de valores de declividade iguais ou superiores a 12\% de área plantada de cana-de-açúcar

\begin{tabular}{c|c|c|c}
\hline MDE & Unitário (ha) & $\begin{array}{c}\text { \% da área plantada } \\
\text { total }\end{array}$ & $\begin{array}{c}\text { \% do território } \\
\text { municipal }\end{array}$ \\
\hline TOPODATA & 742,15 & $2,94 \%$ & $0,18 \%$ \\
SRTM & 242,29 & $0,96 \%$ & $0,06 \%$ \\
ASTER & $3.159,65$ & $12,52 \%$ & $0,78 \%$ \\
\hline
\end{tabular}

Fonte: Autores (2019).

Os mapas referentes às Figuras 16, 17 e 18 exibem o resultado dos valores de declividade da área plantada de cana-de-açúcar no município de Campos dos Goytacazes - RJ segundo os parâmetros elencados pela Lei Estadual n 5.990 de 20 de junho de 2011 (RIO DE JANEIRO, 2011).

A Figura 16 sugere presença de área plantada de cana-de-açúcar em porções centrais do município de Campos dos Goytacazes com distanciamento radial em direção ao norte a partir do centro espacial municipal (estando tais áreas sobre percentuais de declividade não muito significativos) e alguns valores de área plantada seguindo a direção oeste a partir Revista Cerrados, Montes Claros/MG, v. 18, n. 2, p. 69-99, jul./dez.-2020. 
BARBOSA, A. I. G.; REIS, C. H.; MENDONÇA, J. C.; LÄMMLE, L.

O uso de Sensoriamento Remoto para estimar área plantada de cana-de-açúcar em Campos dos Goytacazes - RJ, Brasil

do centro espacial do município (estes estando sobre percentuais significativos de declividade).

Figura 16 - Classes de Declividade iguais ou superiores a 12\% em Campos dos Goytacazes segundo o MDE TOPODATA

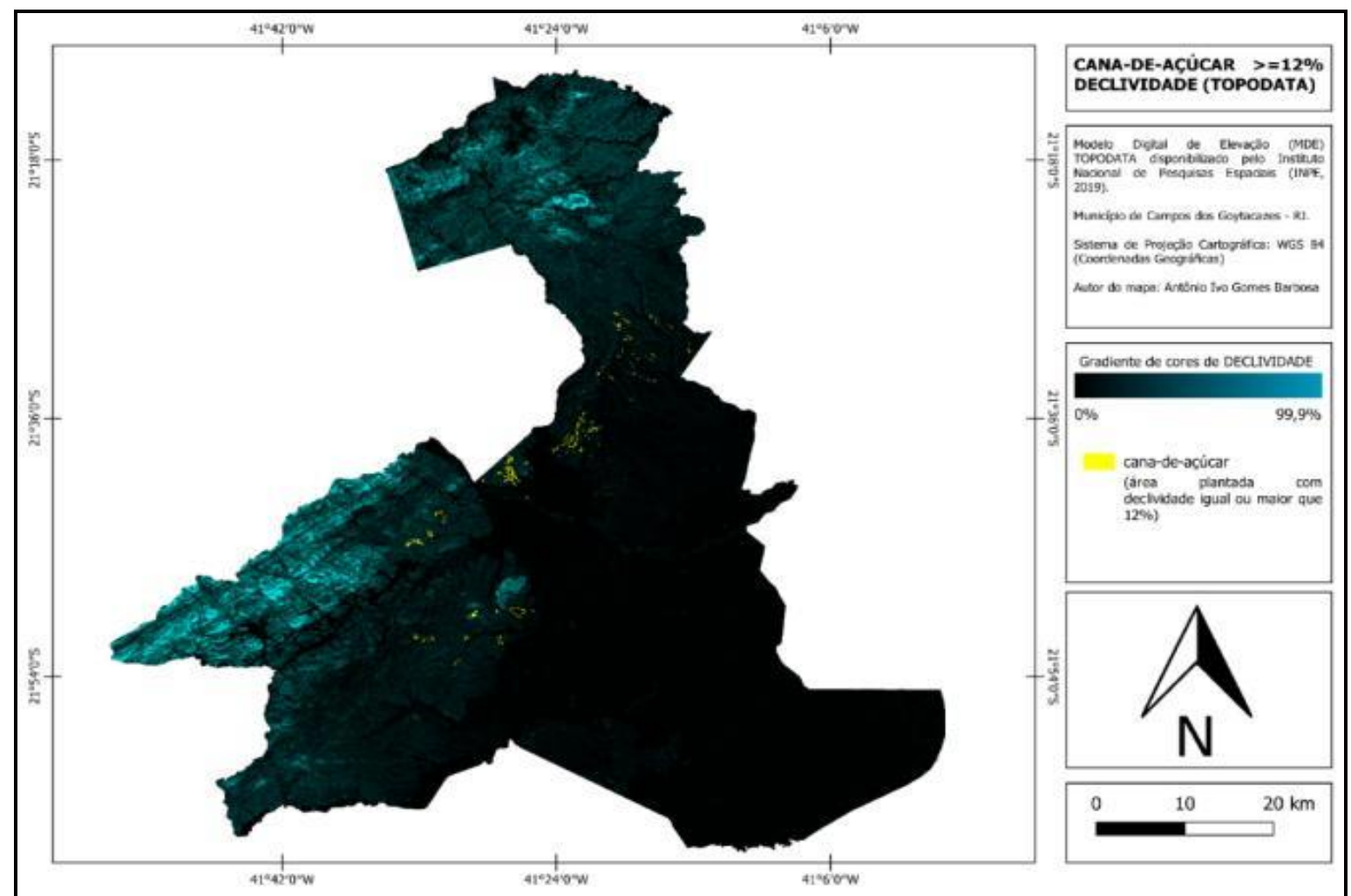

Fonte: Autores (2019).

A Figura 17 mostra pouca presença de área plantada de cana-de-açúcar tanto em porções territoriais com declividades mais significativas ou menos significativas, a julgar pelo exibido no produto cartográfico correspondente a esta figura.

A Figura 18 apresenta presença de área plantada de cana-de-açúcar em vastas porções do município com declividade relativamente significativa. Tal fato ocorre pelo que foi apontado anteriormente, sobre o MDE ASTER indicar a presença de áreas de alto grau de declividade em territórios onde, na realidade, não deveriam existir tais declives. 
BARBOSA, A. I. G.; REIS, C. H.; MENDONÇA, J. C.; LÄMMLE, L.

O uso de Sensoriamento Remoto para estimar área plantada de cana-de-açúcar em Campos dos Goytacazes - RJ, Brasil

Figura 17 - Classes de Declividade iguais ou superiores a 12\% em Campos dos Goytacazes segundo o MDE SRTM

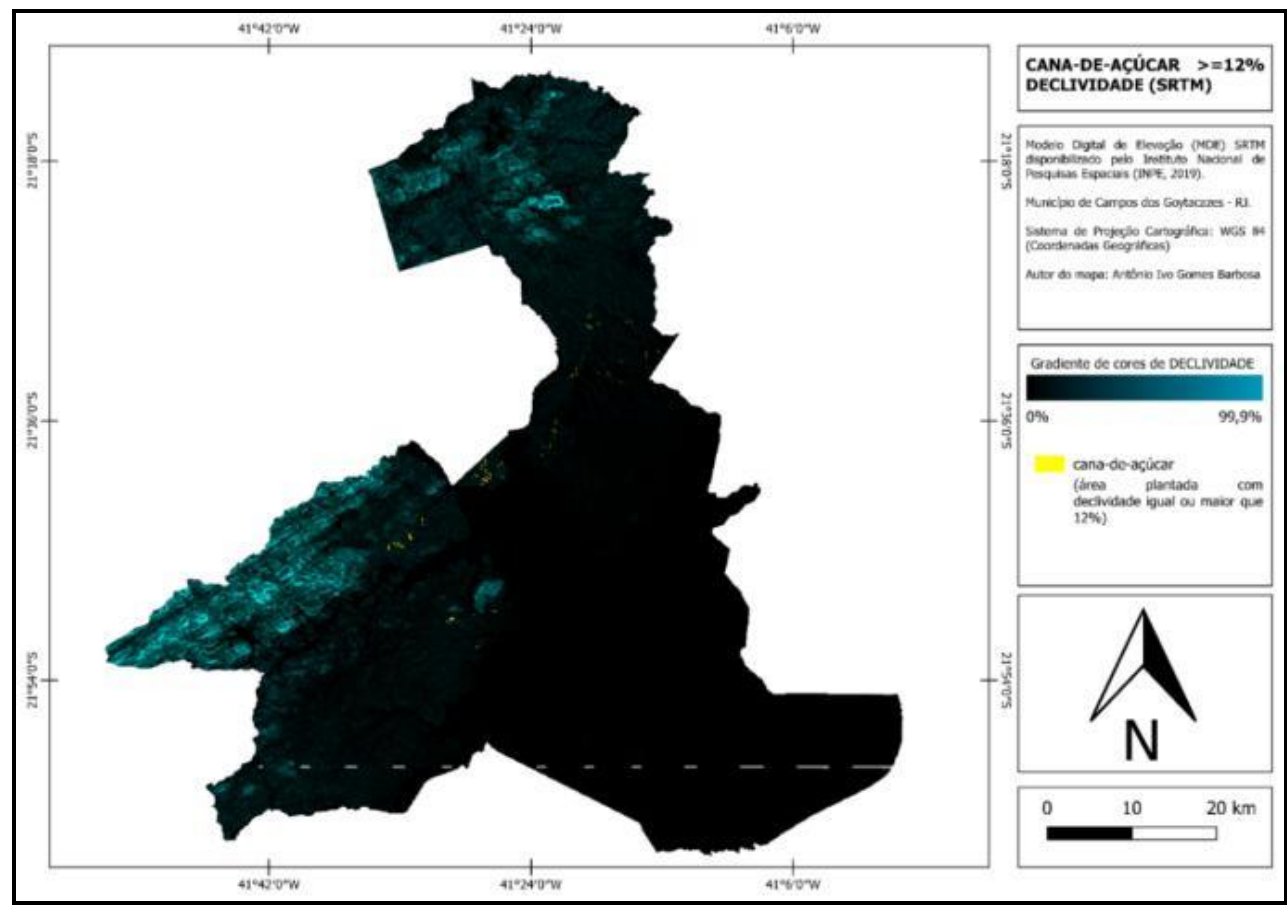

Fonte: Autores (2019).

Figura 18 - Classes de Declividade iguais ou superiores a 12\% em Campos dos Goytacazes segundo o MDE ASTER

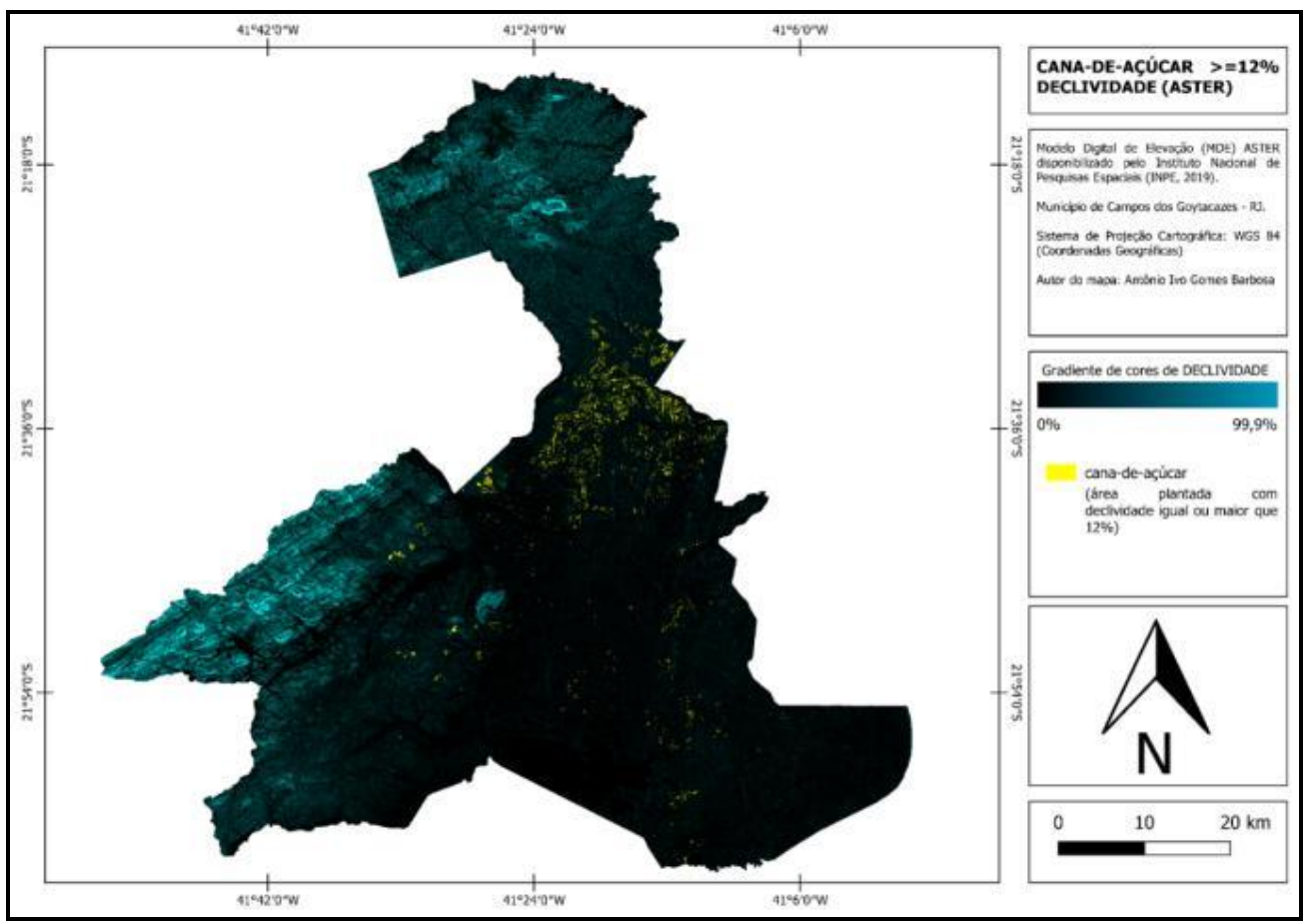

Fonte: Autores (2019).

Revista Cerrados, Montes Claros/MG, v. 18, n. 2, p. 69-99, jul./dez.-2020. 
BARBOSA, A. I. G.; REIS, C. H.; MENDONÇA, J. C.; LÄMMLE, L.

O uso de Sensoriamento Remoto para estimar área plantada de cana-de-açúcar em Campos dos Goytacazes - RJ, Brasil

Os dados prévios de referencial teórico apresentavam estimativa de redução de 57.227,25 ha na área plantada de cana-de-açúcar em Campos dos Goytacazes entre 1990 e 2013, o que endossa um declínio da atividade sucroalcooleira na região com a diminuição do número de usinas de moagem no município entre 1970 e 2019 (BARBOSA, 2019).

Houve grande divergência entre os valores levantados pela CONAB (2019) e IBGE (2019) para o quantitativo de área plantada de cana-de-açúcar no ano-safra 2018/2019, uma vez que a Companhia Nacional de Abastecimento (CONAB) havia apresentado área plantada de 19.200 ha enquanto o Instituto Brasileiro de Geografia e Estatística (IBGE) apresentou uma área plantada de 30.000 ha no município para o referido ano-safra. Tais divergências de valores entraram em consonância com a dificuldade de obtenção de dado oficial que melhor represente a realidade. O presente trabalho levantou uma estimativa de área plantada de 25.238 ha, o que é positivo se forem tomados como parâmetros os valores apresentados pela CONAB e IBGE, uma vez que é um número consideravelmente médio entre ambos (ainda que eles não tenham sido usados como parâmetros em momento algum ao longo da elaboração deste trabalho).

Os modelos digitais de elevação apresentaram valores distintos entre si para diferentes classes de declividade de acordo com critérios da Lei Estadual no 5.990 de 20 de junho de 2011 ( $<12 \%$ e >=12\%). Houve uma variação máxima de 8.138,78 ha entre o menor e o maior valor de classe de declividade $<12 \%$, e de $3.870,11$ ha para declividade $>=12 \%$. Verificou-se considerável distinção entre o maior e o menor valor de área plantada de canade-açúcar com valores de declividade iguais ou superiores a $12 \%$, gerando um equivalente de 2.917,36 ha. No que se refere à análise com o levantamento de dados utilizando os MDE TOPODATA, SRTM e ASTER, sugere-se existência de uma área plantada de cana-de-açúcar entre 242,29 ha e $3.159,65$ ha onde a queima da palha da cana seja permitida por apresentarem declividade do terreno igual ou superior a $12 \%$, o que seria equivalente a um valor entre 9,6\% e 12,52\% do total estimado de área plantada no ano-safra 2017/2018. Tal variação justifica-se a depender do MDE analisado, tendo em vista que existem discrepâncias de valores entre eles. 
BARBOSA, A. I. G.; REIS, C. H.; MENDONÇA, J. C.; LÄMMLE, L.

O uso de Sensoriamento Remoto para estimar área plantada de cana-de-açúcar em Campos dos Goytacazes - RJ, Brasil

\section{CONSIDERAÇÕES FINAIS}

A hipótese de ter havido um significativo declínio de área plantada de cana-deaçúcar no município de Campos dos Goytacazes desde a última estimativa realizada em 2013 foi confirmada, pois segundo o valor levantado no presente trabalho a redução de área plantada foi de 35.921 ha (aproximadamente 8,9\% do território do município de Campos dos Goytacazes - RJ). A fotointerpretação por meio de Interpretação Visual de Polígonos (IVP) para o levantamento de estimativa de área plantada de cana-de-açúcar por Sensoriamento Remoto mostrou-se eficaz, uma vez que os valores levantados se mantiveram entre dois valores de órgãos governamentais oficiais. Contudo, cabe destacar que tal técnica se limita ao conhecimento prévio e interpretação pessoal do fotointérprete que esteja realizando o Processamento Digital de Imagens em Sistema de Informação Geográfica (SIG).

Tamanha disparidade de valores entre os órgãos oficiais do governo e entre os modelos digitais de elevação (MDE) utilizados ampliam a margem de erro, o que talvez seja inviável quando desejar-se obter precisão numérica dos resultados. Em contrapartida, por se tratar de uma área de estudo relativamente extensa, a metodologia utilizada mostrou-se eficiente.

Sugere-se que os órgãos responsáveis se comprometam a criar meios que possibilitem a continuidade desse tipo de monitoramento, uma vez que a geração desses dados geram melhor conhecimento e, consequentemente, melhor gestão do plantio, possibilitando, por exemplo, gerar uma maior produção e menor degradação ao meio ambiente.

\section{AGRADECIMENTOS}

Os autores agradecem a Coordenação de Aperfeiçoamento de Pessoal de Nível Superior (CAPES) pelo financiamento e ao Comitê de Bacia Hidrográfica do Baixo Paraíba do Sul e Itabapoana (CBH BPSI).

\section{REFERÊNCIAS}

Agência Embrapa de Informação Tecnológica. EMBRAPA, 2005. Disponível em: < https://www.agencia.cnptia.embrapa.br/gestor/cana-deacucar/arvore/CONTAG01_68_711200516719.html>. Acesso em 24/07/2020. 
BARBOSA, A. I. G.; REIS, C. H.; MENDONÇA, J. C.; LÄMMLE, L.

O uso de Sensoriamento Remoto para estimar área plantada de cana-de-açúcar em Campos dos Goytacazes - RJ, Brasil

AGUIAR, D. A. de; RUDORFF, B. F. T.; ADAMI, M.; SHIMABUKURO, Y. E. Imagens de sensoriamento remoto no monitoramento da colheita da cana-de-açúcar. Eng. Agríc. [online], [S./l.],, v.29, n.3, p.440-451, 2009

ALVARES, C. A.; DE OLIVEIRA, C. F.; VALADÃO, F. T.; MOLIN, J. P.; SALVI, J. V.; FORTES, C. Sensoriamento Remoto no mapeamento de falhas de plantio em cana-deaçúcar. In.: Congresso Brasileiro de Agricultura de Precisão - CONBAP. 2008.

ARAÚJO, E. S.; SANTOS, J. A. P. O desenvolvimento da cultura da cana-de-açúcar no Brasil e sua relevância na economia nacional. Facider: Revista Científica, Colíder (MT), v. 1, n. 4, p.1-12, 2013. Disponível em: <http://sei-

cesucol.edu.br/revista/index.php/facider/article/view/37/87>. Acesso em: 26 fev. 2019.

AYER, B. E. J.; MINCATO, L. R.; LÄMMLE, L.; SILVA, M. P. F. L.; GAROFALO, T. F. D.; SERVIDONI, E. L.; SPALEVIC, V.; PEREIRA, Y. S. Hydrosedimentological dynamics in the Guarani Aquifer System, Ribeirão Preto, State of São Paulo, Brazil. Agriculture and Forestry, [S./1.], v. 66, n. 1, p. 215-232, 2020.

BARBOSA, A. I. G. Estimativa da área plantada de cana-de-açúcar em Campos dos Goytacazes - RJ utilizando Sensoriamento Remoto. 2019. 78 f. Dissertação (Mestrado em Geografia) - Programa de Pós-Graduação em Geografia, Universidade Federal Fluminense PUCG, Campos dos Goytacazes, RJ, 2019.

BIELENKI JUNIOR, C.; BARBASSA, A. P. Geoprocessamento e recursos hídricos: aplicações práticas. São Carlos, SP: EDUFSCar, 2012. 257 p.

BISINOTTO, E. F. G. A evolução dos engenhos de cana-de-açúcar às usinas sucroenergéticas no Brasil e a aplicabilidade da lei $\mathbf{n}^{\mathbf{0}}$ 11.101/2005 nos dias atuais. 2018. Artigo disponível na página "Boletim Jurídico". Disponível em:

<https://www.boletimjuridico.com.br/doutrina/artigo/4830/a-evolucao-engenhos-cana-acucaras-usinas-sucroenergeticas-brasil-aplicabilidade-lei-n-111012005-dias-atuais>. Acesso em: 27 fev. 2019.

BOLES, S.; XIAO, X.; ZHANG, Q.; MUNKHUTYA, S.; LIU, J.; OJIMA, D. S. $\quad$ Land cover characterization of Temperate East Asia: using multi-temporal image data of VEGETATION sensor. Remote Sensing of Environment, [S./1.], v. 90, p. 477-489, 2004.

CBH BPSI - Comitê de Bacia Hidrográfica do Baixo Paraíba do Sul e Itabapoana, 2019. Disponível em: <http://www.cbhbaixoparaiba.org.br/ocomite.php>. Acesso em 06/04/2019.

COAGRO (Campos dos Goytacazes). Cooperativa Agroindustrial do Estado do Rio de Janeiro. 2019. Disponível em: <http://www.coagro.coop.br/noticias>. Acesso em: 03 jun. 2019.

DE OLIVEIRA, D. A.; HERNANDEZ, F. B. T.; BISPO, R. C.; TEIXEIRA, A. H. C. Produtividade da água em Cana-De-Açúcar irrigada e não irrigada utilizando imagens do 
BARBOSA, A. I. G.; REIS, C. H.; MENDONÇA, J. C.; LÄMMLE, L.

O uso de Sensoriamento Remoto para estimar área plantada de cana-de-açúcar em Campos dos Goytacazes - RJ, Brasil

Satélite Landsat 8. In: anais do XIX Simpósio Brasileiro De Sensoriamento Remoto, Santos/SP, 2019.

EMPRESA BRASILEIRA DE PESQUISA AGROPECUÁRIA - EMBRAPA (Brasil). LANDSAT - Land Remote Sensing Satellite. 2013. Disponível em < https://www.cnpm.embrapa.br/projetos/sat/conteudo/missao_landsat.html>. Acesso em 08 abr. 2019.

EMPRESA BRASILEIRA DE PESQUISA AGROPECUÁRIA - EMBRAPA (Brasil). SRTM - Shuttle Radar Topography Mission. Disponível em:

<https://www.cnpm.embrapa.br/projetos/sat/conteudo/missao_srtm.html/>. Acesso em: 14 out. 2019.

EMPRESA BRASILEIRA DE PESQUISA AGROPECUÁRIA - EMBRAPA. Centro Nacional de Pesquisa de Solos (Rio de Janeiro, RJ). Sistema brasileiro de classificação de solos. 2. ed. - Rio de Janeiro : EMBRAPA-SPI, 2006. 306 p. Disponível em $<$ https://www.agrolink.com.br/downloads/sistema-brasileiro-de-classificacao-dossolos2006.pdf>. Acesso em 29/02/2020.

FERNANDES, Jeferson Lobato. Monitoramento da cultura de cana-de-açucar no estado de São Paulo por meio de imagens SPOT vegetation e dados meteorológicos. Jeferson Lobato Fernandes. -- Campinas, SP: [s.n.], 2009.

FLORENZANO, Teresa Gallotti. Iniciação em Sensoriamento Remoto. 3. ed. ampliada e atualizada. São Paulo: Oficina de Textos, 2011. Disponível em:

<https://ebooks.ofitexto.com.br/epubreader/iniciao-em-sensoriamento-remoto>. Acesso em 01 Mai 2019.

FORMAGGIO, A. R.; SANCHES, I. A. Sensoriamento Remoto em agricultura. São Paulo: Oficina de Textos, 2017.

INSTITUTO BRASILEIRO DE GEOGRAFIA E ESTATÍSTICA - IBGE (Brasil). Campos dos Goytacazes. 2019. Disponível em: https://cidades.ibge.gov.br/brasil/rj/campos-dosgoytacazes/panorama. Acesso em 03/10/2018.

INSTITUTO BRASILEIRO DE GEOGRAFIA E ESTATÍSTICA - IBGE (Brasil). Divisão regional do Brasil em mesorregiões e microrregiões geográficas. IBGE (1990). Disponível em: < https://biblioteca.ibge.gov.br/index.php/biblioteca-

catalogo? view=detalhes\&id=22269> . Acesso em: 24/07/2020.

INPE (Brasil) Divisão de Geração de Imagens: Coordenação geral de observação da Terra. LANDSAT. 2019b. Disponível em em:

<http://www.dgi.inpe.br/documentacao/satelites/landsat>. Acesso em 08 abr. 2019.

INPE (Brasil). CANASAT: Monitoramento de Cana-de-açúcar via imagens de satélite. 2019a Disponível em: < http://www.dsr.inpe.br/laf/canasat/tabelas.html>. Acesso em: 25 fev. 2019. 
BARBOSA, A. I. G.; REIS, C. H.; MENDONÇA, J. C.; LÄMMLE, L.

O uso de Sensoriamento Remoto para estimar área plantada de cana-de-açúcar em Campos dos Goytacazes - RJ, Brasil

LAMEGO, A. R. O homem e o brejo. Rio de Janeiro. IBGE, 1945.

LÄMMLE, L.; BULHÕES, E. M. R. Impactos de obras costeiras na linha de costa: O Caso do Porto do Açu, Município de São João da Barra, RJ. Boletim do Observatório Ambiental Alberto Ribeiro Lamego, [S./l.], v. 13, p. 131-152, 2019.

LUCIANO, A. C. S.; DUFT, D. G.; PICOLI, M. C. A.; ROCHA, J. V.; MAIRE, G.

Estimativa da produtividade de cana-de-açúcar utilizando imagens landsat e random forest. In: Anais do XIX Simpósio Brasileiro de Sensoriamento Remoto, 2019, Santos/SP, 2019.

MENDONÇA, J. C.; FREITAS, R. M.; AGUIAR, D. A.; SOUSA, E. F.; MUNIZ, R. A.; ESTEVES, B. S. Mapeamento das áreas de cana-de-açúcar na Região Norte-Fluminense - RJ por uso de técnicas de Sensoriamento Remoto. Revista de Engenharia Agrícola, Jaboticabal, v. 31, n. 3, p. 561-571, maio 2011.

MENESES, P. R.; ALMEIDA, T. Introdução ao Processamento de Imagens de Sensoriamento Remoto. Brasília: UnB / CNPQ, 2012. 276 p. Disponível em: <http://www.cnpq.br/documents/10157/56b578c4-0fd5-4b9f-b82a-e9693e4f69d8>. Acesso em: 17 dez. 2018.

NASA EARTHDATA (USA). Disponível em: <https://earthdata.nasa.gov/>. 2019. Acesso em: 14 out. 2019.

PARANHOS, P. O açúcar no Norte-Fluminense. 2006. Disponível em:

<http://www.historica.arquivoestado.sp.gov.br/materias/anteriores/edicao08/materia02/texto0 2.pdf>. Acesso em: 02 abr. 2019.

QUARESMA, C.; PEREZ FILHO, A.; BARBOSA, P. DE O.; MORAES, M. B. de; LÄMMLE, L. Influências da Textura e Temperatura dos Solos Sobre a Regeneração do Cerrado na Estação Ecológica de Jataí - Luiz Antônio/SP-Brasil. Revista Do Departamento de Geografia, São Paulo, v. 36, p. 141-154, 2018.

RIO DE JANEIRO. Lei n 5.990, de 20 de junho de 2011. Dispõe sobre a eliminação gradativa da queima da palha da cana-de-açúcar e dá outras providências: Rio de Janeiro, RJ. Disponível em: <https://gov-rj.jusbrasil.com.br/legislacao/1028058/lei-5990-11>. Acesso em: 25/07/2020.

RURAL CENTRO (Brasil). Do açúcar dos antigos engenhos às modernas usinas. 2010. Conteúdo do website "Rural Centro". Disponível em:

$<$ http://ruralcentro.uol.com.br/noticias/do-acucar-dos-antigos-engenhos-as-modernas-usinas25649>. Acesso em: 27 fev. 2019.

SMIDERLE, D. A. V. O multiforme desafio do setor sucroalcooleiro de Campos dos Goytacazes (RJ). 2009. 104 f. Dissertação (Mestrado) - Curso de Pós-graduação em Políticas Sociais, Centro de Ciências do Homem (cch), Universidade Estadual do Norte Fluminense Darcy Ribeiro (uenf), Campos dos Goytacazes, 2009. Disponível em: 
BARBOSA, A. I. G.; REIS, C. H.; MENDONÇA, J. C.; LÄMMLE, L.

O uso de Sensoriamento Remoto para estimar área plantada de cana-de-açúcar em Campos dos Goytacazes - RJ, Brasil

<http://www.uenf.br/Uenf/Downloads/P_SOCIAIS_4856_1274134748.pdf >. Acesso em: 09 abr. 2019.

ZHANG, L. X.; ZHOU, D. C.; FAN, J. W.; HU, Z. M. Comparison of four light use effi ciency models for estimating terrestrial gross primary production. Ecological Modelling, [S./1.], v. 300, p. 30-39, 2015.

\section{Autores}

Antônio Ivo Gomes Barbosa - É Graduado e Mestre em Geografia pela Universidade Federal Fluminense (UFF). Atualmente cursa Licenciatura em Geografia (UFF) e é estagiário pela Associação Pró-Gestão das Águas da Bacia Hidrográfica do Rio Paraíba do Sul (AGEVAP).

Cláudio Henrique Reis - É Graduado em Geografia pela Universidade Federal Fluminense (UFF), Mestre em Sensoriamento Remoto pelo Instituto Nacional de Pesquisas Espaciais (INPE) e Doutor em Geografia pela Universidade Federal do Rio de Janeiro (UFRJ). Atualmente é Professor Associado da Universidade Federal Fluminense (UFF).

José Carlos Mendonça - É Graduado em Engenharia Agronômica pela Universidade Estadual do Norte Fluminense Darcy Ribeiro (UENF), Mestre e Doutor em Produção Vegetal pela mesma universidade. Atualmente é Professor Associado da Universidade Estadual do Norte Fluminense Darcy Ribeiro (UENF).

Luca Lämmle - É Graduado e Mestre em Geografia pela Universidade Federal Fluminense (UFF). Atualmente é Doutorando pelo Programa de Pós-graduação em Geografia da Universidade Estadual de Campinas (UNICAMP).

Artigo recebido em: 09 de maio de 2020.

Artigo aceito em: 26 de junho de 2020.

Artigo publicado em: 19 de agosto de 2020. 